\title{
EVALUATION OF SAFT AMERICA, INC. ELECTROCHEMICAL CAPACITORS
}

\author{
R. B. Wright \\ T. C. Murphy
}

December 1997

Prepared for the U.S. Department of Energy Assistant Secretary for Energy Efficiency and Renewable Energy (EE)

Under DOE Idaho Operations Office

Contract DE-AC07-94ID13223

and

Lawrence-Berkeley National Laboratory

Under Contract No. 4606510 


\section{DISCLAIMER}

This report was prepared as an account of work sponsored by an agency of the United States Government. Neither the United States Government nor any agency thereof, nor any of their employees, makes any warranty, express or implied, or assumes any legal liability or responsibility for the accuracy, completeness, or usefulness of any information, apparatus, product, or process disclosed, or represents that its use would not infringe privately owned rights. Reference herein to any specific commercial product, process, or service by trade name, trademark, manufacturer, or otherwise does not necessarily constitute or imply its endorsement, recommendation, or favoring by the United States Government or any agency thereof. The views and opinions of authors expressed herein do not necessarily state or reflect those of the United States Government or any agency thereof. 


\section{DISCLAIMER}

Portions of this document may be illegible electronic image products. Images are produced from the best available original document. 


\section{CONTENTS}

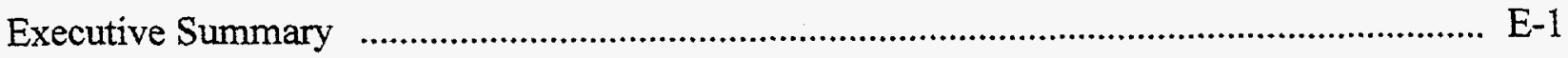

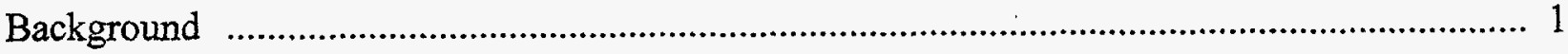

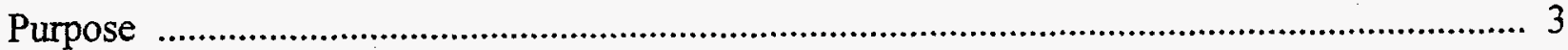

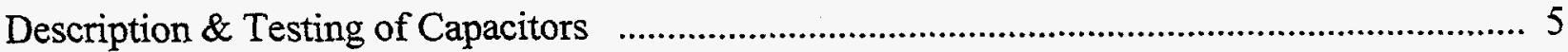

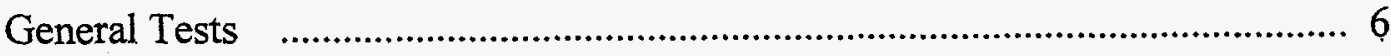

Constant-Current Tests ........................................................................... 6

Constant-Power Tests .................................................................................. 7

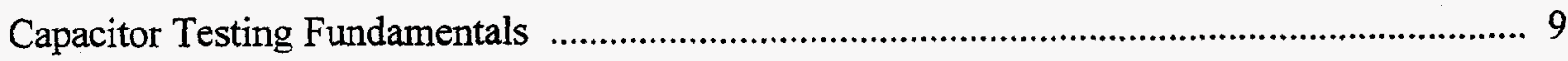

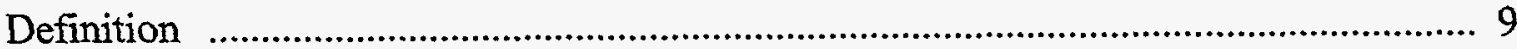

Energy and Power Supplied by a Capacitor ............................................................ 10

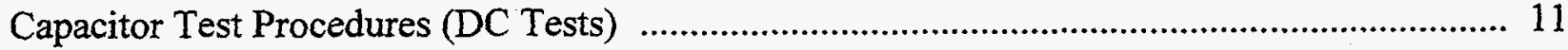

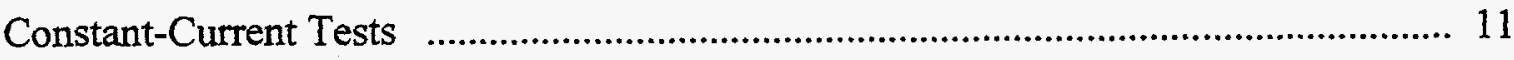

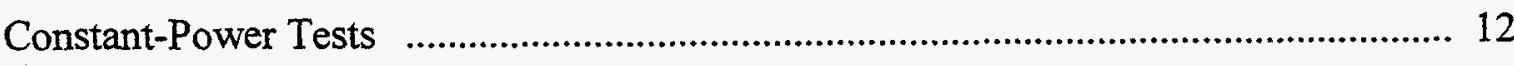

Leakage-Current Test …................................................................................. 13

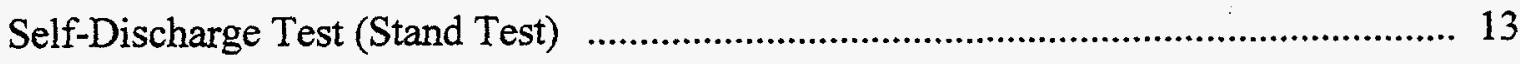

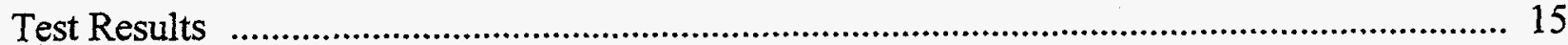

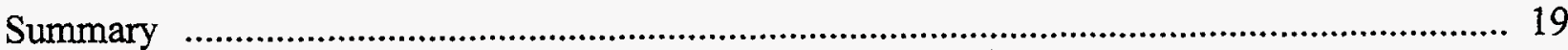

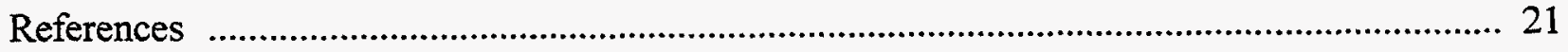

FIGURES

1. Photograph of SAFT America, Inc. electrochemical capacitors ..................................... 3

\section{TABLES}

1. Cell characteristics supplied by SAFT America, Inc. for each capacitor. ……….............. 5

2. Measured as-tested weights for the SAFT capacitors ………………................................. 6

\section{APPENDIX}

A. Graphic Figures for SAFT America, Inc. Capacitors 


\section{EXECUTIVE SUMMARY}

Ten capacitors were received from SAFT America, Inc. for testing by the Idaho National Engineering and Environmental Laboratory (INEEL) Automotive Systems and Technology (AS\&T) Department's Energy Storage Technologies (EST) Laboratory. All the capacitors were based on an experimental carbon electrode/non-aqueous electrolyte technology. The ten capacitors were rated at $3.0 \mathrm{~V}$ with capacitances varying from 40 to $62 \mathrm{~F}$.

Constant-current and constant-power tests were conducted on each capacitor; the test parameters were set according to the ratings of each device and from information supplied by SAFT America, Inc. The constant-current test was the first test to be conducted on the capacitors and consisted of three charge and discharge cycles between 3 and $1.5 \mathrm{~V}$ over a range of discharge currents such that the minimum discharge time of each device was kept at approximately 10 seconds. The charging current was kept constant at $0.5 \mathrm{~A}$ for these tests. During initial testing two of the devices did not successfully charge and were eliminated from further testing. The constant-current tests were then rerun on the remaining eight capacitors using a charge and discharge range of 3 to $0 \mathrm{~V}$. The constant-current charging current was again kept at $0.5 \mathrm{~A}$. It was observed that the increase and decrease of the capacitor voltage during charging and discharging did not occur in a linear manner indicating that the capacitance of the devices was a function of the capacitor voltage. From these data the capacitance and equivalent series resistance (ESR) of each capacitor was calculated as a function of the constant-current discharge current used during the tests. Collectively, the capacitance of the devices ranged from 51 to $64 \mathrm{~F}$ at a $1 \mathrm{~A}$ constant-current discharge and decreased in a fairly linear manner to values ranging from $32 \mathrm{~F}$ to $48 \mathrm{~F}$ at a $12 \mathrm{~A}$ constant-current discharge. The ESR values ranged from 38 to 78 milliohms at a $1 \mathrm{~A}$ constant-current discharge, decreasing nonlinearly to values ranging from 18 to 56 milliohms at a constant-current discharge of $12 \mathrm{~A}$. For both the capacitance and ESR values, the values of the individual devices tended to. be grouped together according to the specific carbon material from with they were fabricated. The capacitors with the largest capacitance and greatest ESR were made using Maxsorb-PVA; those with the lowest capacitance and smallest ESR were made using Norit SX Ultra-PVA. The one device tested that was made using Norit SX-Ultra PVA but "pushing" the various processes was intermediate between the other two groups of capacitors. This capacitor did, however, have the lowest ESR values and had the smallest decrease in capacitance with increasing constant-current discharge current. 
The constant-power test was the next test to be conducted on the devices. A $0.5 \mathrm{~A}$ constant-current charge was used in the tests; the constant-power discharge was varied with the maximum level adjusted to keep the discharge time at 10 seconds or greater. Three cycles at each test condition was used; the voltage range used for the tests was 3 to $1.5 \mathrm{~V}$. From these tests the specific energy as a function of specific power was calculated for each device. Collectively, the specific energy of the capacitors ranged from approximately 1.4 to $1.8 \mathrm{Wh} / \mathrm{kg}$ at approximately $63 \mathrm{~W} / \mathrm{kg}$, decreasing in a linear manner to values ranging from approximately 1.1 to $1.4 \mathrm{Wh} / \mathrm{kg}$ at approximately $330 \mathrm{~W} / \mathrm{kg}$. The specific energy and specific power performance of the capacitors was again found to be influenced by the particular carbon material from which they were fabricated. The greatest specific energy at a given specific power was observed from those devices made using Maxsorb-PVA, followed by Norit SX Ultra-PVA with "extra" processing, and finally those made using Norit SX Ultra-PVA without the "extra" processing. 


\section{BACKGROUND}

The electrochemical capacitor devices described in this report were deliverables from Lawrence Berkeley National Laboratory (LBNL), Contract No. 4606510 with SAFT America, Inc., as part of LBNL's exploratory research program. Dr. Kimio Kinoshita is the Program Manager at LBNL. The contract was in support of the U.S. Department of Energy's (DOE) exploratory electrochemical energy storage program which includes development projects for a wide variety of advanced high-energy/high-power energy storage systems for electric and hybrid vehicle programs. The DOE is currently developing various electrochemical capacitors as candidate power assist devices for the Partnership for a New Generation of Vehicles (PNGV) fast-response engine requirements. ${ }^{1}$ The LBNL contract with SAFT America, Inc., was intended to evaluate various activated carbon-based electrode formulations and develop an electrical model of the double-layer capacitor. The goal is to design and deliver prototypes meeting the DOE requirement of $>1000 \mathrm{~W} / \mathrm{kg}, 16 \mathrm{Wh} / \mathrm{kg}$. Deliverables were sent to the INEEL EST Laboratory for independent testing and evaluation. The following report describes performance testing on ten devices received September 2, 1996. Due to the initial performance of these early devices, life-cycle testing was not conducted. Additional devices, with improved performance, are expected to be tested. Future results will be reported in a follow-on report. 


\section{PURPOSE}

The purpose of this report is to present the electrical performance for ten electrochemical capacitors supplied by SAFT America, Inc. (see Figure 1) that were received for testing at the INEEL during September, 1996.-5 All tests were conducted in the EST Laboratory which is managed by the AS\&T Department at the INEEL.

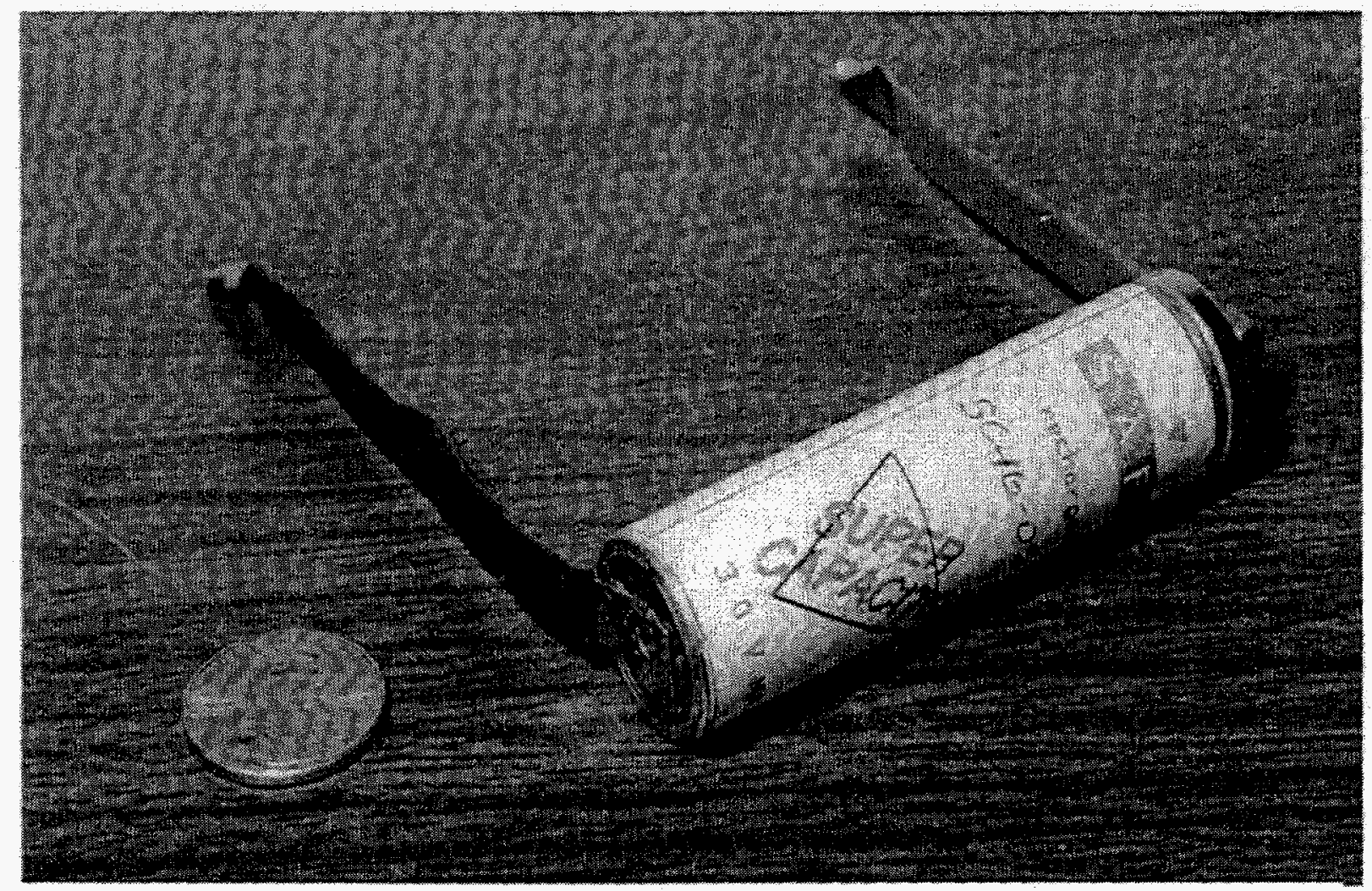

Figure 1. SAFT America, Inc. carbon-based, non-aqueous, electrochemical capacitor in 18650 size can. 


\section{DESCRIPTION \& TESTING OF CAPACITORS}

The ten capacitors were received September 2, 1996. The cell characteristics and testing recommendations, as provided by SAFT America, Inc., are presented in Table 1, and the measured as-tested weights of the ten capacitors are presented in Table 2.

Table 1. Cell characteristics supplied by SAFT America, Inc.

\begin{tabular}{|c|c|c|c|c|}
\hline Cell No. & Weight (g) & Capacitance $(\mathbf{F})^{2}$ & $\begin{array}{l}\text { Impedance } \\
\text { (milliohms) }^{3}\end{array}$ & Composition \\
\hline $58-002$ & 24.1 & 47.7 & 32.8 & Norit SX Ultra - PVA \\
\hline $58-003$ & 24.1 & 46.8 & 32.4 & \\
\hline $58-005$ & 24.0 & 46.8 & 32.1 & \\
\hline $58-008$ & 23.9 & 42.7 & 34.0 & \\
\hline $58-009$ & 24.0 & 40.4 & 34.1 & \\
\hline $46-003$ & 25.3 & 55.2 & 28.1 & Norit SX Ultra - PVA ${ }^{4}$ \\
\hline $50-001$ & 23.9 & 58.1 & 40.4 & \\
\hline $50-002$ & 23.7 & 56.9 & 40.3 & Maxsorb - PVA \\
\hline $50-003$ & 23.5 & 58.1 & 40.3 & \\
\hline $50-004$ & 23.6 & 61.8 & 40.3 & \\
\hline \multicolumn{5}{|c|}{ 1. Bare cell weight: does not include outside connection and wrapping } \\
\hline \multicolumn{5}{|c|}{ 2. Capacitance measured under $1 \mathrm{~A}$ constant current } \\
\hline \multicolumn{5}{|c|}{ 3. Resistance measured under a current charge of $1 \mathrm{~A}$} \\
\hline \multicolumn{5}{|c|}{ 4. $\quad$ Best possible design with PVA/Norit by pushing the various processes } \\
\hline \multicolumn{5}{|c|}{ Recommendations } \\
\hline p & \multicolumn{4}{|c|}{$\begin{array}{l}\text { Cycle cells between } 1.5 \text { and } 3.0 \mathrm{~V} \text {. Testing below } 1.5 \mathrm{~V} \text { may result in minor corrosion } \\
\text { problem, which would affect cycle life (but not safety). Long-term design will include } \\
\text { all aluminum hardware. }\end{array}$} \\
\hline 2. & \multicolumn{4}{|c|}{$\begin{array}{l}\text { SAFT America, Inc. has tested all these cells at up to } 20 \mathrm{~A} \text {. Current limitation has not } \\
\text { been evaluated, but it is assumed that in view of the internal connection, this value is } \\
\text { close to the upper limit. }\end{array}$} \\
\hline $\begin{array}{l}\text { S } \\
\text { sh }\end{array}$ & \multicolumn{4}{|c|}{$\begin{array}{l}\text { Solvent: Acetonitrile. Do not heat cell above } 80^{\circ} \mathrm{C} \text {. Normal operating temperature } \\
\text { should be limited to } 60^{\circ} \mathrm{C} \text {. }\end{array}$} \\
\hline
\end{tabular}


Table 2. Measured as-tested weights for the SAFT capacitors.

\begin{tabular}{|c|c|c|}
\hline \multirow{2}{*}{ Capacitor No. } & \multicolumn{2}{|c|}{ Weight } \\
\cline { 2 - 3 } & Grams & Kilograms \\
\hline $58-002$ & 30.339 & 0.030339 \\
\hline $58-003$ & 30.390 & 0.030390 \\
\hline $58-005$ & 30.187 & 0.030187 \\
\hline $58-008$ & 30.096 & 0.030096 \\
\hline $58-009$ & 30.258 & 0.030258 \\
\hline $46-003$ & 31.898 & 0.031898 \\
\hline $50-001$ & 30.680 & 0.030680 \\
\hline $50-002$ & 29.997 & 0.029997 \\
\hline $50-003$ & 30.053 & 0.030053 \\
\hline $50-004$ & 30.602 & 0.030602 \\
\hline
\end{tabular}

\section{General Tests}

- After removing the cell from its packaging, weigh it to the nearest $0.01 \mathrm{~g}$ and record results.

- The leads coming out of each cell are color coded with "red" and "black" markings indicating where the corresponding "+" and " - " leads to the tester should be connected.

- Charge at $0.1 \mathrm{~A}$ (100 milliamperes) constant-current unless specified otherwise.

- Clamp voltage for 10 seconds at the charge and discharge voltage endpoints specified on each cycle.

- Complete three test cycles at each test condition.

\section{Constant-Current Tests}

- Voltage limits are 3.0 to $1.5 \mathrm{~V}$. (The constant-current tests were also conducted using a $3.0 \mathrm{~V}$ to $0.0 \mathrm{~V}$ discharge range using a $0.5 \mathrm{~A}$ constant-current charge.)

- Begin discharging each capacitor at constant currents of $1,2,4,6,8,10$, etc. amperes until a discharge time of approximately 10 seconds is attained. (Note: SAFT America, Inc. stated that they have tested all of these capacitors to $20 \mathrm{~A}$.) 


\section{Constant-Power Tests}

- Voltage limits are $3.0 \mathrm{~V}$ to $1.5 \mathrm{~V}$.

- Discharge each capacitor at a constant-power of $2,4,8,10,12$, etc. watts. The constantpower discharge level should be adjusted such that the discharge time is greater than approximately 10 seconds, at which point the test should be stopped for a given capacitor. 


\section{CAPACITOR TESTING FUNDAMENTALS ${ }^{6-7}$}

\section{Definition}

Capacitance is a measure of the ability of a device, a capacitor, to store energy in the form of separated charge or as an electric field.

The capacitance, $\mathrm{C}$, of a capacitor is defined as the ratio of the charge $\mathrm{Q}$ (in units of coulombs, $1 \mathrm{e}^{-}=1.602 \times 10^{-19}$ coulomb) on either of two spatially separated conductors to the potential difference $\mathrm{V}_{\mathrm{ab}}$ (in volts) between the conductors.

$$
\mathrm{C}=\mathrm{Q} / \mathbf{V}_{\mathrm{ab}}
$$

The unit of capacitance is the farad defined as one coulomb per volt. A farad is also defined to be one ampere-second/volt. A first-order model for an electrochemical capacitor includes a capacitor $C$ in series with a resistor $R_{s}$ and a series inductor $L$. A resistor $R_{p}$ in parallel with the capacitor is also included in this model. $R_{s}$ is usually referred to as the equivalent series resistance (ESR) and contributes to energy loss during capacitor charging and discharging. $R_{p}$ simulates energy loss due to capacitor self-discharge and is often referred to as the leakagecurrent resistance. $\mathrm{L}$ is the inductance of the capacitor that results primarily from the construction of the capacitor and is usually small.

Capacitance (in farads) as defined above can be expressed as:

$$
\mathbf{C}=\mathbf{Q} / \mathbf{V}
$$

where $\mathrm{Q}$ is the charge on the capacitor in coulombs and $\mathrm{V}$ is the potential difference in volts. For a series $R C$ circuit (neglecting $R_{p}$ and $L$ ) the voltage as a function of time can be expressed as:

$$
V_{0}-V(t)=I * R_{s}+\left[Q_{0}-Q(t)\right] / C
$$

where $V_{0}$ is the initial voltage across the capacitor, $Q_{0}$ is the initial charge on the capacitor having a capacitance $\mathrm{C} ; \mathrm{I}$ is the current flowing in the circuit and $\mathrm{R}_{\mathrm{s}}$ is the series resistance. During a constant-current charging test, $\mathrm{I}=\mathrm{I}_{\mathrm{c}}=$ constant set by the test during charging; $\mathrm{V}_{\mathrm{o}}=0$ if the capacitor is totally discharged or $V_{0}=V_{0}$ if the capacitor has been charged to a voltage $V_{0}$. For $\mathrm{Q}_{\mathrm{o}}=0$ then $\mathrm{Q}(\mathrm{t})=\mathrm{I}_{c} \mathrm{t}$, or if $\mathrm{Qo}=\mathrm{Q}$ o then $\mathrm{Q}(\mathrm{t})=\mathrm{Q}_{\mathrm{o}}+\mathrm{I}_{c} \mathrm{t}$ so that:

$$
V_{c}(t)=\left(V_{o}+I_{c} R_{s}\right)+\left(I_{c} / C\right) t
$$

From equation (3) is can be seen that a plot of the capacitor voltage, $V_{c}(t)$ versus the test time should be a straight line with an intercept at $t=0$ equal to $\left(V_{o}+I_{c} R_{s}\right)$ that will allow the determination of the equivalent series resistance, $R_{s}$. The slope of the straight line should be positive and equal to $\left(I_{c} / C\right)$ that will allow the determination of the capacitor's capacitance. In practice, "real-world" capacitors are observed to deviate from the ideal-capacitor model in that the capacitor voltage as a function of charge time during a constant-current charge is nonlinear. 
During a constant-current discharge test $\mathrm{V}(\mathrm{t}=0)=\mathrm{V}_{0}, \mathrm{I}_{\mathrm{d}}=$ constant set by the test (note that by convention a discharge current is negative in sign as compared to a charging current); $Q_{0}$ $=\mathrm{V}_{0} \mathrm{C}$ and $\mathrm{Q}(\mathrm{t})=\mathrm{Q}_{\mathrm{o}}-\mathrm{I}_{\mathrm{d}} \mathrm{t}$ so that:

$$
V_{d}(t)=\left(V_{o}-I_{d} R_{s}\right)-\left(I_{d} / C\right) t
$$

As for the constant-current charge test, a plot of the capacitor voltage, $V_{d}(t)$, as a function of constant-current discharge test time should result in a straight line with an intercept at $t=0$ equal to $\left(V_{o}-I_{d} R_{s}\right)$ from which the equivalent series resistance, $R_{s}$, can be determined. The slope of the straight line should be negative and equal to $-\left(\mathrm{I}_{d} / \mathrm{C}\right)$ and permits the determination of the capacitor's capacitance, $\mathrm{C}$.

As mentioned above the terms $\left(V_{o}+I_{c} R_{s}\right)$ for charging and $\left(V_{o}-I_{d} R_{s}\right)$ for discharging can be used to calculate the Equivalent Series Resistance (ESR) during charging and discharging of the capacitor by the $\mathrm{IR}_{\text {step }}$ method that monitors the voltage on the capacitor immediately after the current applied to the capacitor has been changed. In practice, the first measurement data point is several to several tens of milliseconds after the start of the constant-current charge or discharge step, which is usually accurate enough for the determination of the ESR value as described below.

\section{Energy and Power Supplied by a Capacitor}

For a capacitor having a capacitance $C$ and charged to an initial voltage $V_{i}$ that is then discharged to a final voltage $V_{f}$, the energy (in joules) extracted is:

$$
E=(1 / 2) C V_{i}^{2}\left[1-\left(V_{f} / V_{i}\right)^{2}\right]
$$

For example, if the capacitor is discharged to $1 / 2$ of its initial voltage $V_{f}=1 / 2 V_{i}$ then the energy withdrawn is $3 / 4$ of the maximum available, i.e.:

$$
E=(3 / 4)(1 / 2) C V_{i}^{2}
$$

Similarly, the total energy available in the capacitor is when $V_{f}=0$ then:

$$
E=(1 / 2) C V_{i}^{2}
$$

Since power $P$ [in watts, where 1 watt $=1$ ampere $\times 1$ volt $=(1$ coulomb/second $) \times(1$ joule/coulomb) $=1$ joule/second] is equal to the energy expended over a time interval $\Delta t$ (in seconds):

$$
\mathbf{P}=\mathbf{E} / \Delta \mathbf{t}
$$

The specific energy and power can be obtained by dividing by the mass (in $\mathrm{kg}$ ) or volume (in liters) of the capacitor respectively. 


\section{CAPACITOR TEST PROCEDURES (DC TESTS)}

\section{Constant-Current Test}

1. Determination of capacitor capacitance

2. Determination of equivalent series resistance (ESR).

3. The working energy (also known as the ideal stored energy) and power densities can also be determined.

4. Test cycle:

- Charge the capacitor at a constant specified current to the specified working voltage.

- Hold at this voltage for 10 to 20 seconds.

- Discharge the capacitor at a constant-current to a specified voltage (generally to 0 V).

- Hold at this voltage for 10 to 20 seconds.

These steps constitute one test cycle that is generally repeated three times. The maximum currents $\left(\mathrm{I}_{\text {test }}\right.$ in amperes) to use for these tests are generally kept such that the charge and discharge times are approximately equal to 10 seconds.

If the voltage as a function of charge and discharge time follows the ideal-capacitor model [equations (3) and (4)] the capacitance of the capacitor can be calculated from the slope of the voltage versus charge or discharge time using:

$$
\mathrm{C}=\left(\mathrm{I}_{\text {test }}\right)\left(\mathrm{t}_{\text {test }}\right) / \Delta \mathrm{V}
$$

where $\Delta V$ is the voltage range used in the test and $t_{\text {test }}$ is the measured time in seconds that it takes the capacitor to discharge from the starting voltage (usually the maximum specified working voltage) to the ending voltage (generally zero volts). If the voltage behavior of the capacitor deviated significantly from that of an ideal-capacitor then the capacitance can be determined by the total amount of charge (ampere-seconds) charged into the capacitor during a constant-current charge or discharged from it during a constant-current discharge divided by the voltage change on the capacitor.

The working (also referred to as the ideal stored) energy densities can then be calculated using:

$$
\mathrm{E}_{\mathrm{w}} / \text { Mass }=(1 / 2)\left(\mathrm{I}_{\text {test }}\right)\left(\mathrm{t}_{\text {tes }}\right) \Delta \mathrm{V} /(3600 * \mathrm{M})
$$


seconds to time in hours. The volumetric energy density is given by:

$$
\mathrm{E}_{\mathrm{w}} / \text { Volume }=(1 / 2)\left(\mathrm{I}_{\text {test }}\right)\left(\mathrm{t}_{\text {test }}\right) \Delta \mathrm{V} /\left(3600 * \mathrm{~V}_{\text {cap }}\right)
$$

in $\mathrm{W} \cdot \mathrm{h} / \mathrm{L}$, where $\mathrm{V}_{\text {cap }}$ is the volume in liters of the capacitor.

In the constant-current tests the current $(\mathrm{I})$ is suddenly changed at the beginning and end of the charge/discharge portions of the test cycle. The equivalent series resistance (ESR) is calculated at the beginning of the charge and the discharge cycle using:

$$
\mathrm{ESR}=(\Delta V)_{\mathrm{IR} \mathrm{step}} \mathbf{I}_{\mathrm{IR} \mathrm{step}}
$$

where $(\Delta V)_{\mathbb{R} \text { step }}$ is the voltage change that occurs during the change in current, $I_{\mathbb{R} \text { step }}$, at the beginning of the constant-current charging and discharging of the capacitor. The ESR value is given in ohms and is generally found to vary with the constant-current charge or discharge test value.

\section{Constant-Power Test}

1. Determination of specific energy densities $(W \cdot h / \mathrm{kg}$ and $W \cdot h / L)$ and specific power densities (W/kg and W/L).

2. Test cycle

- The capacitor is charged at a specified constant current to a specified voltage.

- The capacitor is held at this voltage for 10 to 20 seconds.

- A constant power discharge is started and the capacitor is discharged to a specified voltage (generally to $1 / 2$ the working voltage that results in the extraction of $3 / 4$ of the total energy available from the capacitor).

- The capacitor is then held at this voltage for 10 to 20 seconds.

- These steps constitute one test-cycle that is generally repeated three times.

For each constant-power discharge portion of the test cycle the energy (W·s $=$ joules) is calculated by summing $V^{*} I^{*} \Delta t$ (V in volts, $I$ in amperes and $\Delta t$ in seconds) during the discharge. The specific energy densities are then calculated using:

$$
\mathbf{E}_{\mathrm{s}} / \text { Mass }=\Sigma\left[V(t)^{*} I(t) * \Delta t\right]_{\text {discharge }} /\left(3600^{*} \mathbf{M}\right)
$$


in $\mathrm{W} \cdot \mathrm{h} / \mathrm{kg}$, were $\mathrm{M}$ is the mass of the capacitor in $\mathrm{kg}$, and

$$
\mathbf{E}_{\mathrm{s}} / \text { Volume }=\Sigma\left[\mathrm{V}(\mathrm{t})^{*} \mathrm{I}(\mathbf{t}) * \Delta t\right]_{\text {discharge }} /\left(3600^{*} \mathrm{~V}_{\text {cap }}\right)
$$

in $\mathrm{W} \cdot \mathrm{h} / \mathrm{L}$ where $\mathrm{V}_{\text {cap }}$ is the volume of the capacitor in liters.

Under conditions of a constant-power test the specific power, $\mathrm{P}_{\mathrm{s}}$, is set by the test and the specific power densities corresponding to the specific energy densities of equations (13) and (14) would be this power divided by the mass of the capacitor (in $\mathrm{kg}$ ) or the volume of the capacitor (in liters) respectively.

\section{Leakage-Current Test}

1. The leakage-current, $I_{L}(t)$, is the current required to maintain the capacitor at a specified voltage, $V_{i}$. The leakage-current is time dependent and only approaches a constant value after the voltage has been applied to the capacitor for, generally, a number of hours.

2. Determines the value of the parallel resistor, $R_{p}$, in the simple circuit model of the capacitor.

$$
R_{p}(t)=V_{i} /(t)
$$

where $V_{i}$ is the initial voltage on the capacitor and $I(t)$ is the time dependent current required to maintain this voltage at its initial value.

3. Test cycle:

- The capacitor is charged to a specified voltage using a specified constant-current and maintained at that voltage for approximately twenty-four hours or until the required current to maintain the voltage has come to a stable value.

- The current required to maintain the capacitor at the specified voltage should be measured with a tester that has the capability to measure small current (fractions of a milliampere). Generally measurement are made at one-minute intervals for the first hour and then at five-minute intervals during the remainder of the test.

\section{Self-Discharge Test (also known as the Stand Test)}

1. Measures the self-dissipation of the capacitor, i.e. those internal processes that cause the capacitor to discharge when not connected to a load. 
2. Measures the time dependent self-discharge energy loss factor SDLF $(t)$ that results from measuring the time dependence of the capacitor voltage, $\mathrm{V}(\mathrm{t})$, when the capacitor is not connected to an external load:

$$
\operatorname{SDLF}(t)=1-\left[V(t) / V_{i}\right]^{2}
$$

where $V_{i}$ is the initial voltage on the capacitor. The SDLF $(t)$ value permits the determination of the amount of energy remaining in the capacitor [by using equations (5) or (7)] after it has been charged to a voltage $V_{i}$ and then placed in a condition when it is not connected to an external load.

3. Test cycle:

- The capacitor is charged to a specified voltage, $\mathrm{V}_{\mathrm{i}}$, using a specified constant current charge and held at that voltage for 30 minutes.

- The capacitor is then placed on open-circuit and the voltage measured over a period of approximately 72 hours, or as specified. The measuring equipment should have a high input impedance in order to minimize its affects on the capacitor discharge.

For the first three hours, the time increment between voltage measurements should be one minute or less. For the remainder of the test, measurements should be made every 10 minutes or less. 


\section{TEST RESULTS}

The first test that was run on the capacitors was the constant-current test. A representative constant-current test consisting of three cycles at each constant-current discharge current is shown in Figure A-1 that presents the capacitor potential (volts) as a function of test time (seconds) for capacitor \#58-002. As is shown for this test the first step in each test cycle is a $0.5 \mathrm{~A}$ constant-current charge to $3.0 \mathrm{~V}$, a 10 second hold at this voltage, followed by a $2 \mathrm{~A}$ constant-current discharge to $0 \mathrm{~V}$, followed by a 10 second hold at this voltage. This test cycle was repeated three times. From Figure A-1 it can be seen that the voltage during the $0.5 \mathrm{~A}$ constant-current charge is somewhat nonlinear as a function of test time as compared to the idealcapacitor model that predicts a linear time dependence [equation (3)]. The change in voltage during the $2 \mathrm{~A}$ constant-current discharge is observed to be more linear as predicted by the idealcapacitor model [equation (4)]. Also seen in this figure is the IR step change in the voltage at the start of the constant-current discharge due to the ESR of the capacitor. For the following constant-current tests the only portion of the test that was changed was the value of the discharge current. The test current corresponding to the test shown in Figure A-1 is shown in Figure A-2. The constant-current charge at $0.5 \mathrm{~A}$ can be seen as well as the $2 \mathrm{~A}$ constant-current discharge portions of the test. During the portions of the test when the voltage was held constant at either $3 \mathrm{~V}$ or $0 \mathrm{~V}$ the current is observed to change with test time that is due to the leakage-current of the capacitor. Similarly, in Figures A-3 and A-4 are shown the voltage and current as a function of test time for capacitor \#58-002 for a constant-current test that used a 12 A constant-current discharge. A closer examination of the deviation of the test time dependence of the potential of capacitor \#58-002 is shown in Figures A-5, A-6, A-7, and A-8 that show the experimental values of the potential during charging and discharging (cycle \#2 from each test sequence) as compared with the calculated potential using the ideal-capacitor model given by equations (3) and (4). The $\log _{(10)}$ of the test time is used in these plots in order to more easily visualize the differences between the experimental and theoretical values. Values for the capacitance, $C$, and the series resistance, $R_{s}$, used in the equations were the experimentally determined values from the constant-current tests. The values for $\mathrm{C}$ were: $55.8 \mathrm{~F}$ for the $0.5 \mathrm{~A}$ constant-current charge; $50.2 \mathrm{~F}$ for the $2 \mathrm{~A}$ discharge, and $38.2 \mathrm{~F}$ for the $12 \mathrm{~A}$ discharge. The corresponding values of $R_{\mathrm{s}}$, were: $0.0648 \mathrm{ohms}$ for the $0.5 \mathrm{~A}$ charge, $0.0355 \mathrm{ohms}$ for the $2 \mathrm{~A}$ discharge, and $0.0331 \mathrm{ohms}$ for the 12 A discharge. Figures A- 6 and A-8 are plots of the potential difference between the experimental and theoretical values for the charge and discharge portions of the test cycle for the 2 and $12 \mathrm{~A}$ constant-current tests. The major deviations in both tests occur at the intermediate to longer test times for the charge and discharge portions of the test. These deviations probably result from the fact that the value of the capacitance of the capacitor is changing in a nonlinear manner with changing capacitor potential. The effect of the changing capacitance would be to change the slope of the voltage versus time plots that in turn would cause both positive and negative deviations from the ideal-capacitor model [refer to equations (3) and (4)]. 
As stated previously, the first test to be run on each capacitor was the constant-current test. Initially, the capacitors were charged to $3 \mathrm{~V}$ and discharged to $1.5 \mathrm{~V}$. This test was rerun by discharging the devices to $0 \mathrm{~V}$. Capacitors \#58-008 and \#58-009 would not accept a charge during the first series of constant-current tests. As a result no further tests were run on these two capacitors. Figures A-9 and A-10 are plots of the discharge potential as a function of discharge time for capacitor \#58-002 for discharge ranges of $3 \mathrm{~V}$ to $1.5 \mathrm{~V}$ and 3 to $0 \mathrm{~V}$, respectively; Figures A-11 and A-12 are for capacitor \#58-003; Figures A-13 and A-14 are for capacitor \#58-005; Figures A-15 and A-16 are for capacitor \#46-003; Figures A-17 and A-18 are for capacitor $\# 50-001$; Figures $A-19$ and A-20 are for capacitor $\# 50-002$; Figures $A-21$ and A-22 are for capacitor \#50-003; and Figures A-23 and A-24 are for capacitor \#50-004. The capacitance of each capacitor was calculated using equation (9). The measured capacitance as a function of the constant-current discharge are plotted in Figure A-25 for the 3 to $1.5 \mathrm{~V}$ constant-current discharge test and in Figure A-26 for the $3 \mathrm{~V}$ to $0 \mathrm{~V}$ constant-current discharge tests. As can be seen in these figures the measured capacitance values for capacitors \#58-002, \#58-003 and \#58-005, that all used the same carbon material (refer to Table I), were grouped together. So to, were the measured capacitance values for capacitors \#50-001, \#50-002, \#50-003 and \#50-004 that also have the same carbon material. The latter group of capacitors had the highest initial capacitance (at a 1 A constant-current discharge) but their capacitance decreased more rapidly with increasing discharge current than the \#58-series devices. Capacitor \#46-003 had an intermediate initial capacitance value that decreased with approximately the same slope as the \#58-series devices.

The average ESR values, calculated using equation (12) for the discharge portion of the constant-current test and averaged for the three test cycles, are presented in Figure A-27 for the 3 to $1.5 \mathrm{~V}$ tests and in Figure A-28 for the 3 to $0 \mathrm{~V}$ tests. One again the measured ESR values for the various devices are grouped together according to the carbon material used in their fabrication. The \#58-series devices had (generally) the lowest ESR, the \#46-003 device an intermediate value, and the \#50-series devices had the highest values. The ESR values were also observed to generally decrease with increasing discharge current.

The constant-power test was the next test conducted. A 0.5 A constant-current charge was used to charge the capacitor to $3 \mathrm{~V}$ followed by a constant voltage hold at $3 \mathrm{~V}$ for 10 seconds. The capacitor was then discharged using a constant-power discharge from 3 to $1.5 \mathrm{~V}$ in turn followed by a 10 seconds clamp on the voltage at $1.5 \mathrm{~V}$ prior to the next charging cycle. An example of the three cycle test is shown in Figure A-29 for capacitor \#58-002. The capacitor voltage as a function of test time is shown for a 2 watt constant-power test sequence. The test current as a function of test time for this test sequence is shown in Figure A-30. Shown in Figures A-31 to A-38 are the constant-power test data (voltage as a function test time) for the eight capacitors respectively. From these data and the measured weight of each capacitor the 
specific energy as a function of specific power was calculated using equation (13). These results are shown in Figure A-39 for each of the eight capacitors. The specific energy can be seen to decrease with increasing specific power in a fairly linear manner for all of the capacitors. The performance of the capacitors are again observed to group together according to the specific carbon material from which they were fabricated. Thus, devices \#58-002, \#58-003 and \#58-005 were grouped together and had the lowest specific energy (approximately $1.4 \mathrm{Wh} / \mathrm{kg}$ at $60 \mathrm{~W} / \mathrm{kg}$ ). Capacitor \#46-003 had a greater specific energy $(1.5 \mathrm{Wh} / \mathrm{kg}$ at $60 \mathrm{~W} / \mathrm{kg}$ ) but it had the smallest amount of change in specific energy with increasing specific power of all of the capacitors. The capacitors possessing the largest specific energies were \#50-001, \#50-002, $\# 50-003$ and \#50-004 that were all made from the same carbon material. The performance range of the \#50-series group of devices varied more than that of the \#58-series capacitors and their specific energy decreased faster with increasing specific power than the other capacitors. 


\section{SUMMARY}

Ten capacitors supplied by SAFT America, Inc. were tested to determine their capacitance and equivalent series resistance as a function constant-current discharge current, and their specific energy as a function of specific power. Constant-current and constant-power tests were conducted on each capacitor; the test parameters were set according to the ratings of each device and from information supplied by SAFT America, Inc. The constant-current test was the first test to be conducted on the capacitors and consisted of three charge and discharge cycles between 3 and $1.5 \mathrm{~V}$, and between 3 and $0 \mathrm{~V}$ over a range of discharge currents such that the minimum discharge time of each device was kept at approximately 10 seconds or greater. The charging current was kept constant at $0.5 \mathrm{~A}$ for these tests. During initial testing two of the devices (\#58-008 and \#58-009) did not successfully charge and were eliminated from further testing. It was observed that the increase and decrease of the capacitor voltage during charging and discharging did not occur in a linear manner indicating that the capacitance of the devices was a functions of the capacitor voltage. From the constant-current test data the capacitance and equivalent series resistance (ESR) of each capacitor was calculated as a function of the constantcurrent discharge current used during the tests. Collectively, the capacitance of the devices ranged from 51 to $64 \mathrm{~F}$ at a $1 \mathrm{~A}$ constant-current discharge and decreased in a fairly linear manner to values ranging from 32 to $48 \mathrm{~F}$ at a $12 \mathrm{~A}$ constant-current discharge. The ESR values ranged from 38 to 78 milliohms at a $1 \mathrm{~A}$ constant-current discharge, decreasing nonlinearly to values ranging from 18 to 56 milliohms at a constant-current discharge of $12 \mathrm{~A}$. For both the capacitance and ESR values, the values of the individual devices tended to be grouped together according to the specific carbon material from which they were fabricated. The capacitors with the largest capacitance and greatest ESR were made using Maxsorb-PVA; those with lowest capacitance and smallest ESR values were made using Norit SX Ultra-PVA. The one device tested that was fabricated using a Norit SX Ultra-PVA but "pushing" the various processes was intermediate between the other two groups of capacitors. However, this capacitor did have the lowest ESR values and had the smallest decrease in capacitance with increasing constant-current discharge current.

The constant-power test was the next test to be conducted on the devices. A $0.5 \mathrm{~A}$ constant-current charge was used in the tests; the constant-power discharge was varied with the maximum level adjusted to keep the discharge time at 10 seconds or greater. Three cycles at each test condition was used; the voltage range used for the tests was 3 to $1.5 \mathrm{~V}$. From these tests the specific energy as a function of specific power was calculated for each device. 
Collectively, the specific energies of the capacitors ranged from approximately 1.4 to 1.8 $\mathrm{Wh} / \mathrm{kg}$ at approximately $63 \mathrm{~W} / \mathrm{kg}$. The specific energy decreased in a linear manner to approximately $1.1 \mathrm{Wh} / \mathrm{kg}$ to $1.4 \mathrm{Wh} / \mathrm{kg}$ at approximately $330 \mathrm{~W} / \mathrm{kg}$. The specific energy performance of the capacitors was observed to form groups of devices having similar behavior according to the specific carbon material used in their fabrication. Those capacitors prepared from Maxsorb-PVA had the best performance, followed by the capacitor prepared from Norit SX Ultra-PVA with "extra" processing. The devices prepared from Norit SX Ultra-PVA without the "extra" processing had the lowest specific energies at a given specific power.

Based on the performance data presented, these early devices will not meet the PNGV technical targets for hybrid traction applications. As a result, further testing of these deliverables was not performed. Additional devices from SAFT America, Inc., with improved performance, are expected and will be subjected to limited performance testing. Results from future testing will be published at a later date. 


\section{REFERENCES}

1. R. A. Sutula, "The Department of Energy's High-Power Energy Storage Programs," in Preprints of the Annual Automotive Technology Development Customers' Coordination Meeting, Volume I Oral Presentations, October 28-November 1, 1996.

2. G. Chagnon, "SAFT Supercapacitors: Design and Performance," Proceedings of the 37th Power Sources Conference, Cherry Hill, NJ, June 17-20, 1996, p. 120.

3. T. Murphy and P. B. Davis, "Electrochemical Capacitors," Proceedings of the Symposium on Electrochemical Capacitors , F. M. Delnick and M. Tomkiewicz, eds., Volume 95-29 (The Electrochemical Society, Inc., Pennington, NJ, 1996) p. 269.

4. T. C. Murphy, R. B. Wright, and R. A. Sutula, "Performance of Electrochemical Capacitors," Proceedings of the 6th International Seminar on Double Layer Capacitors and Similar Energy Storage Devices, Volume 6, December 9-11, 1996.

5. T. C. Murphy, R. B. Wright, and R. A. Sutula, "U. S. Department of Energy Electrochemical Capacitor Development and Testing Activities," Proceedings of the Symposium on Electrochemical Capacitors II, F. M. Delnick, D. Ingersoll, X. Andrieu and K. Naoi, eds., Volume 96-25 (The Electrochemical Society, Inc., Pennington, NJ, 1997), p. 258.

6. J. R. Miller and A. F. Burke, "Electric Vehicle Capacitor Test Procedures Manual, Revision 0," published October 1994, Report DOE/ID-10491.

7. A. F. Burke, "Electrochemical Capacitors for Electric and Hybrid Vehicles - The DOE Program and the Status of the Technology - 1993," published October 1994, Report INEL-94/0036. 
APPENDIX A

GRAPHIC FIGURES

FOR

SAFT AMERICA, INC. CAPACITORS 
A-2 


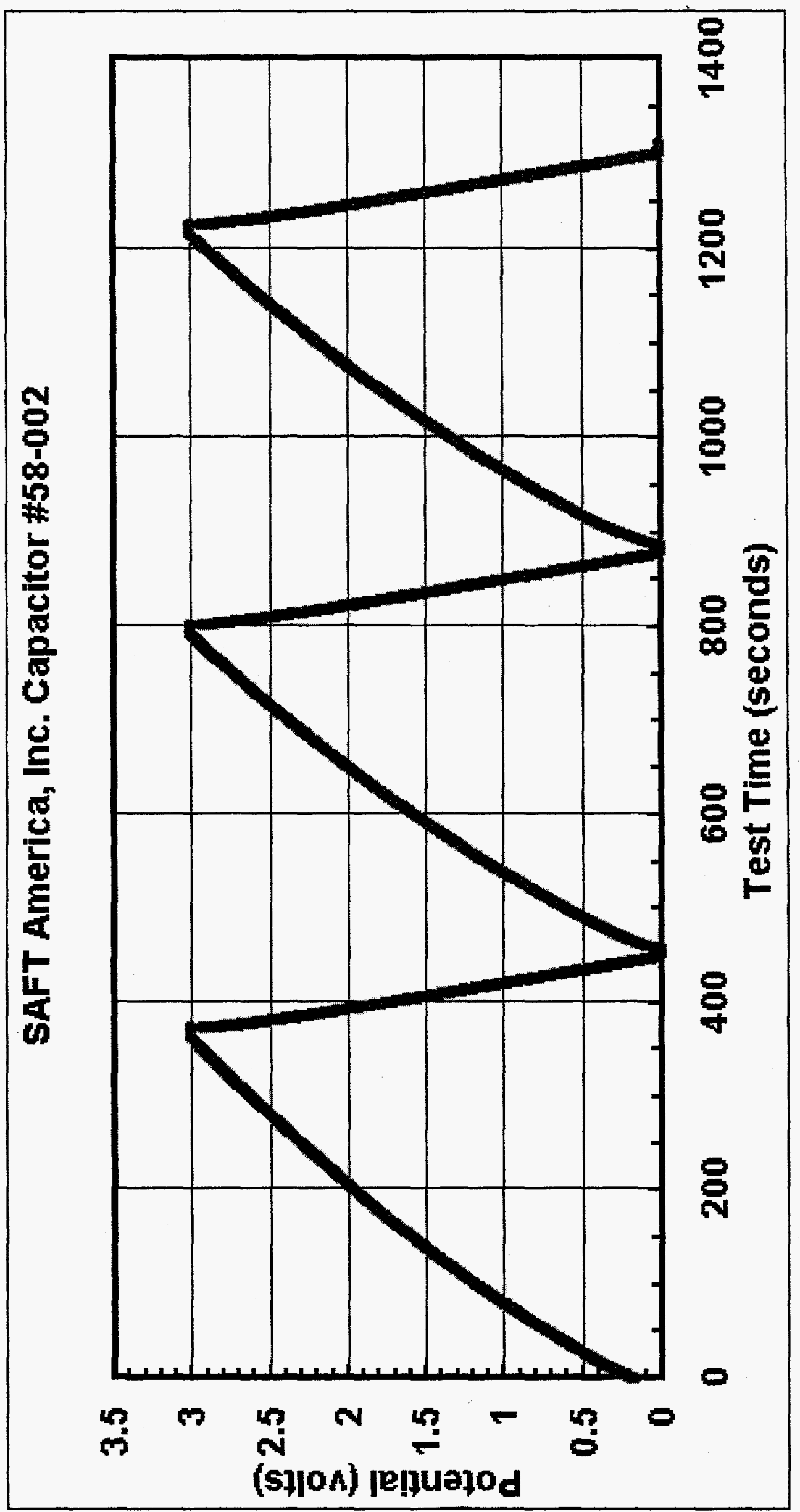

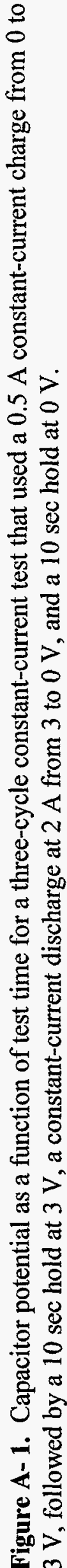




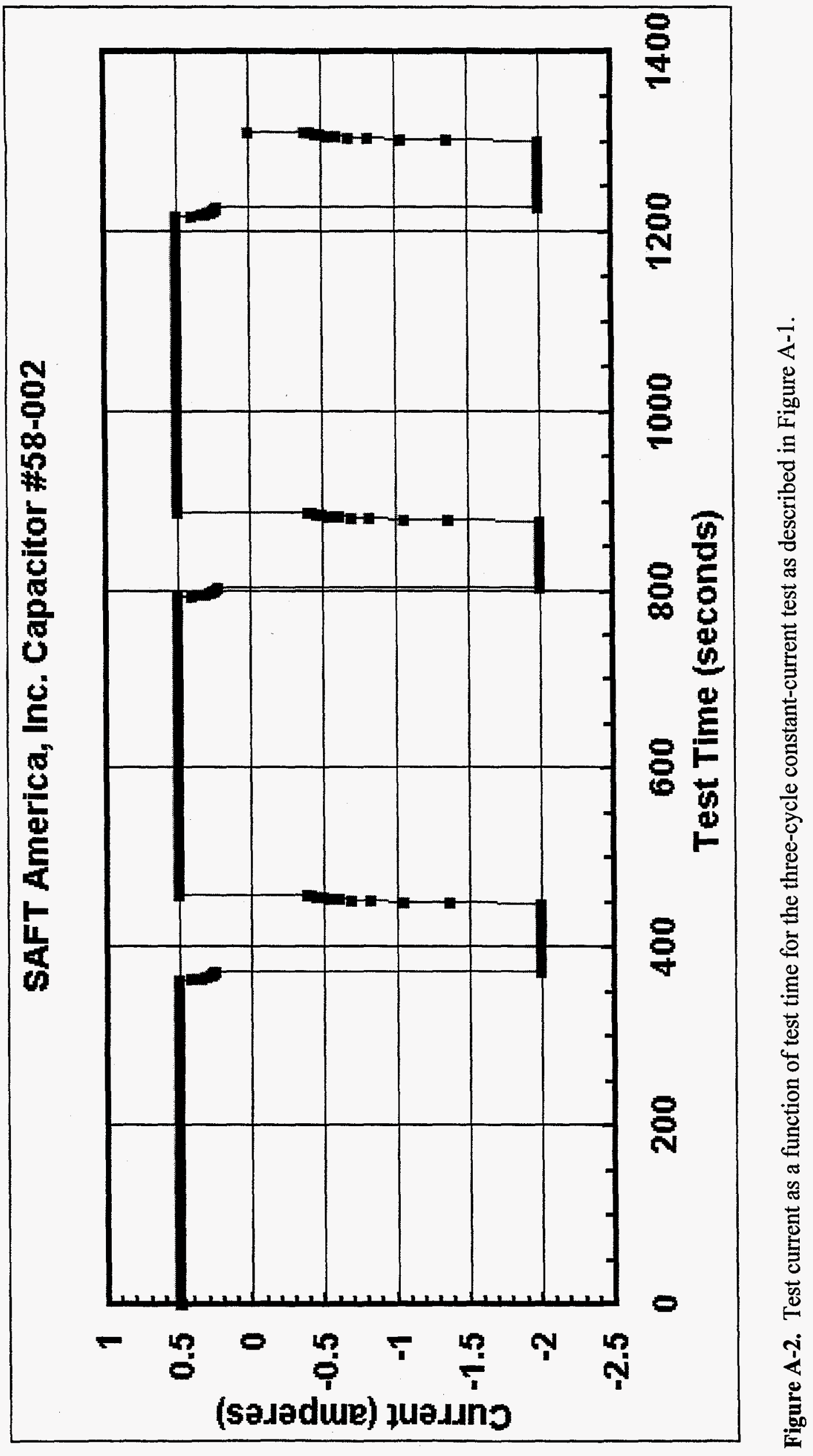




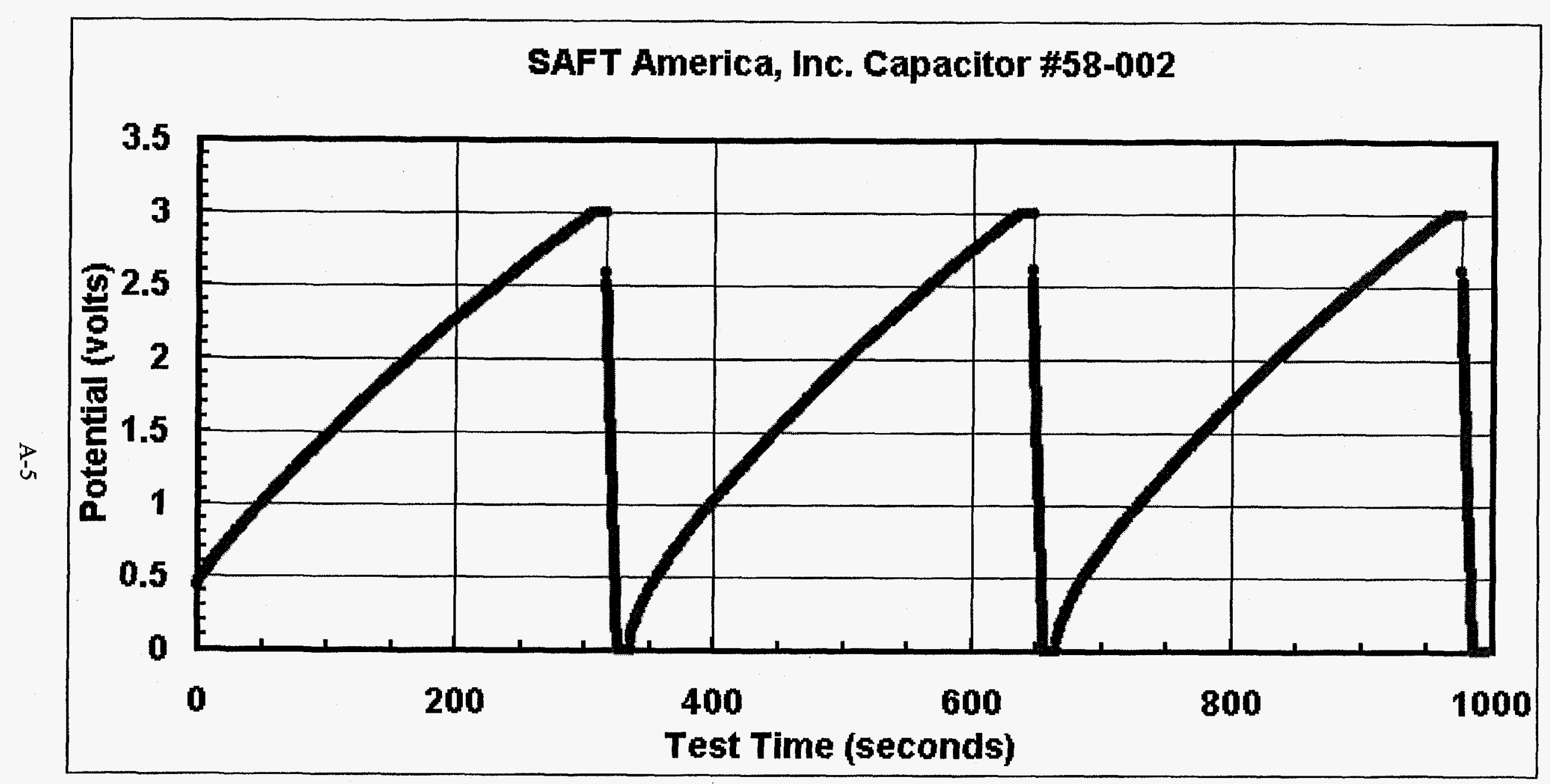

Figure A-3. Capacitor potential as a function of test time for a three-cycle constant-current test that used a $0.5 \mathrm{~A}$ constant-current charge from 0 to $3 \mathrm{~V}$, followed by a $10 \mathrm{sec}$ hold at $3 \mathrm{~V}$, a constant-current discharge at 2 A from 3 to $0 \mathrm{~V}$, and a $10 \mathrm{sec}$ hold at $0 \mathrm{~V}$. 


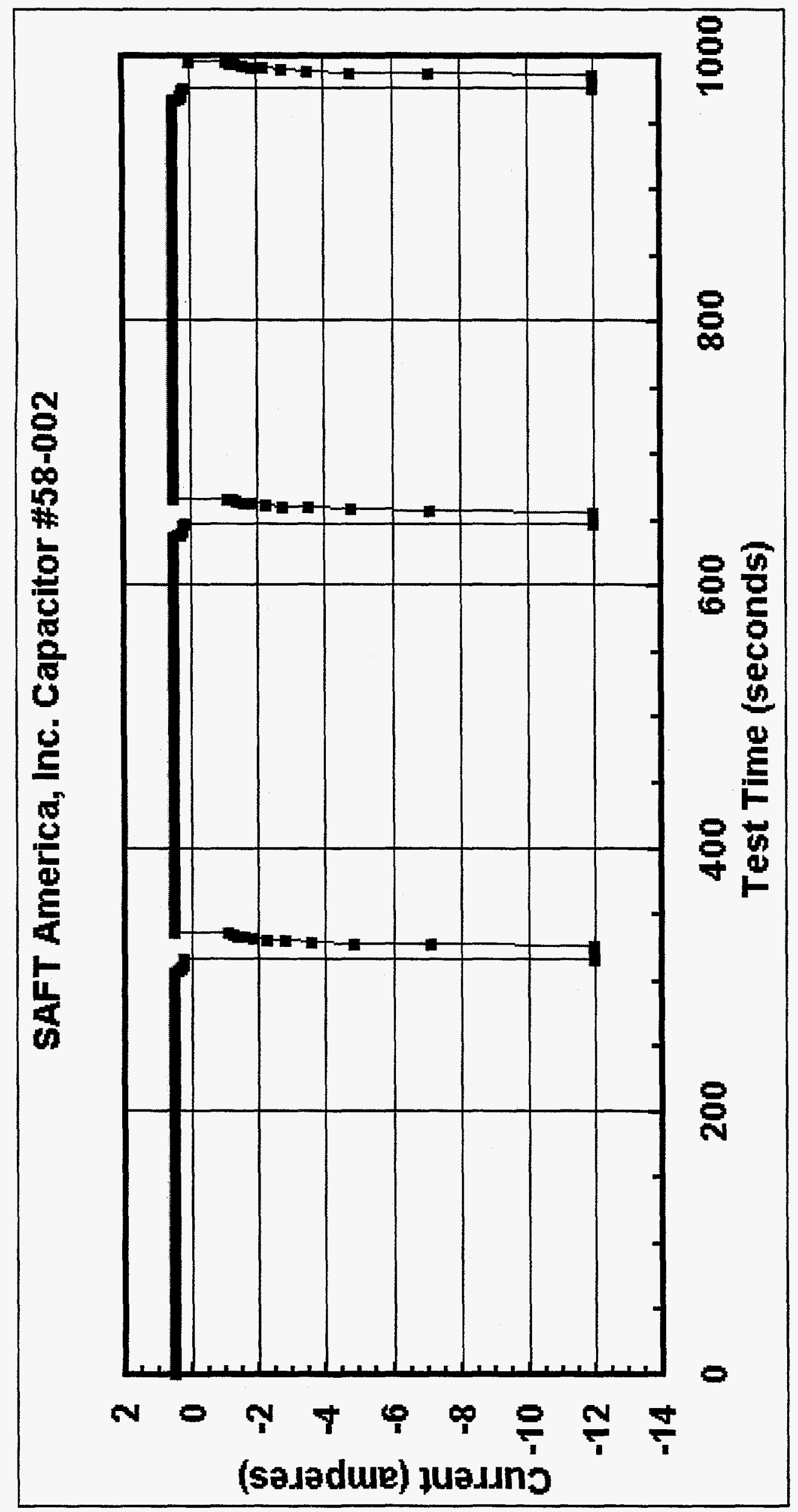

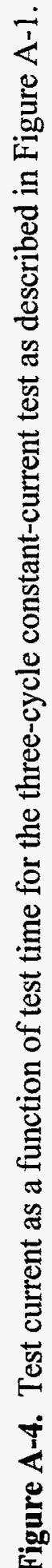




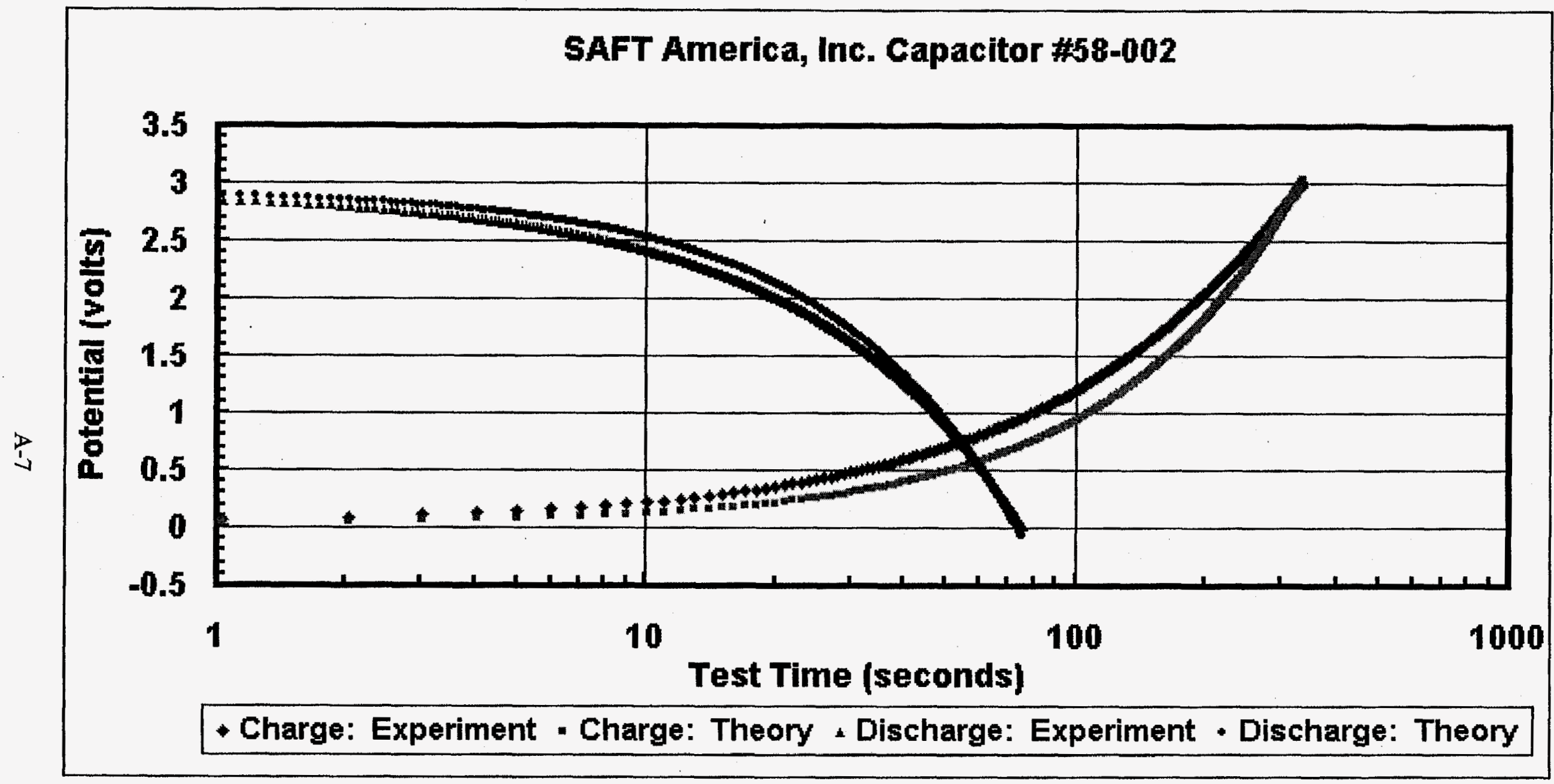

Figure A-5. Experimental and calculated (using the theoretical ideal-capacitor model) values of the charge and discharge potential as a function of test time for a $0.5 \mathrm{~A}$ constant-current charge from 0 to $3 \mathrm{~V}$, and a $2 \mathrm{~A}$ constant-current discharge from 3 to $0 \mathrm{~V}$. 


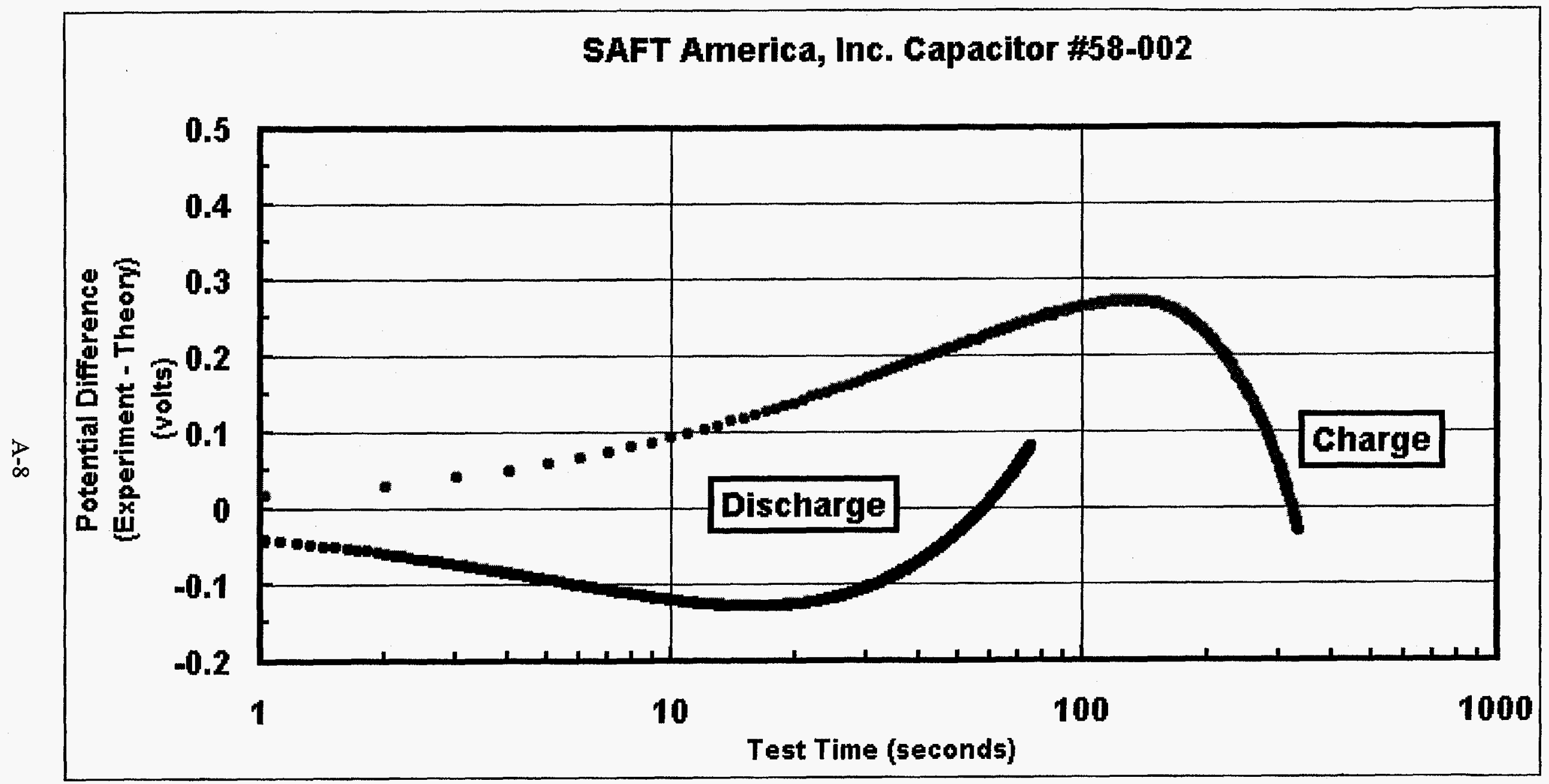

Figure A-6. Calculated potential difference (experimental-theoretical) as a function of test time for the $0.5 \mathrm{~A}$ constant-current charge and $2 \mathrm{~A}$ constant-current discharge test data shown in Figure A-5. 


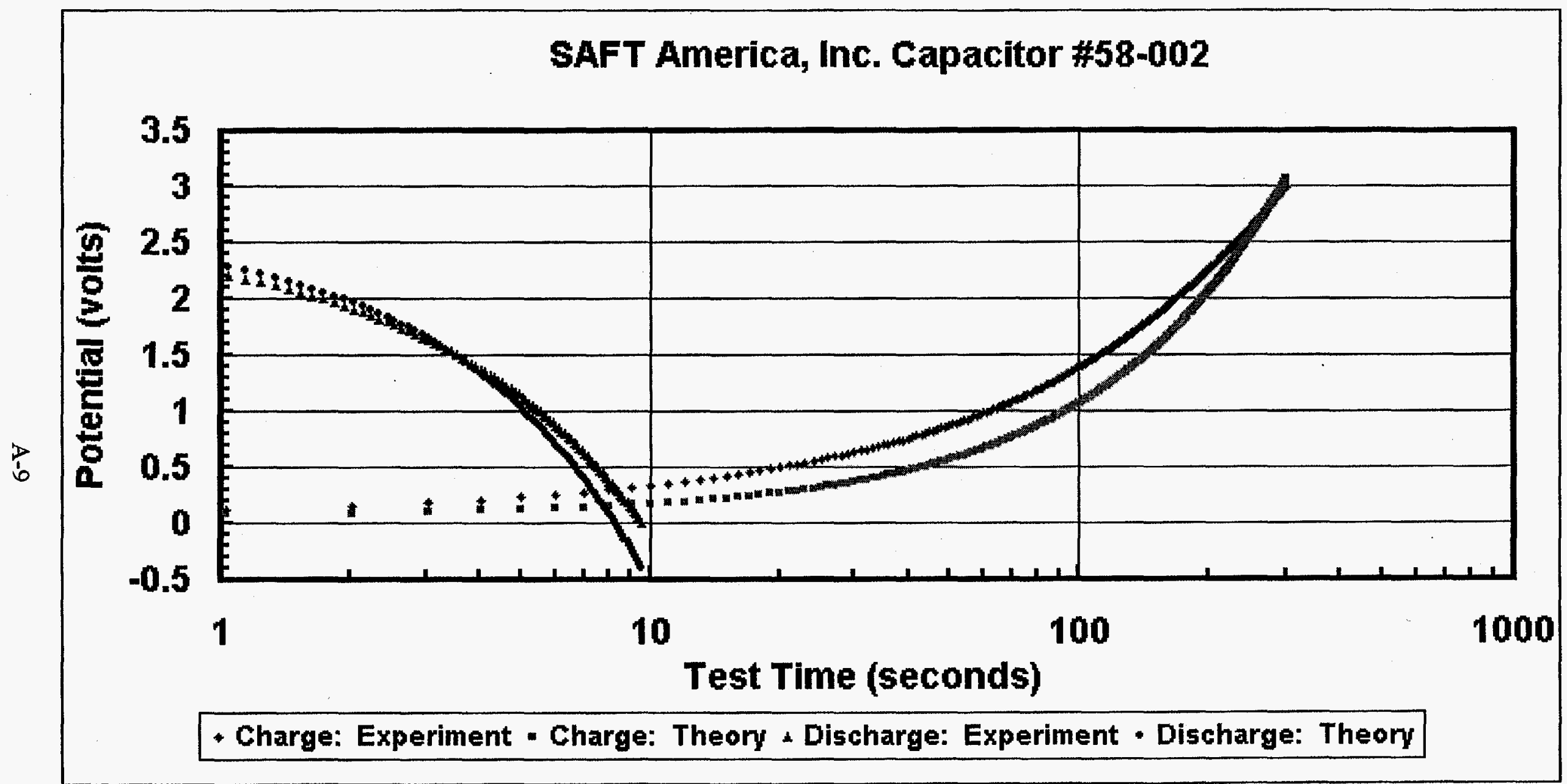

Figure A-7. Experimental and calculated (using the theoretical ideal-capacitor model) values of the charge and discharge potential as a function of test time for a $0.5 \mathrm{~A}$ constant-current charge from 0 to $3 \mathrm{~V}$, and a $12 \mathrm{~A}$ constant-current discharge from 3 to $0 \mathrm{~V}$. 


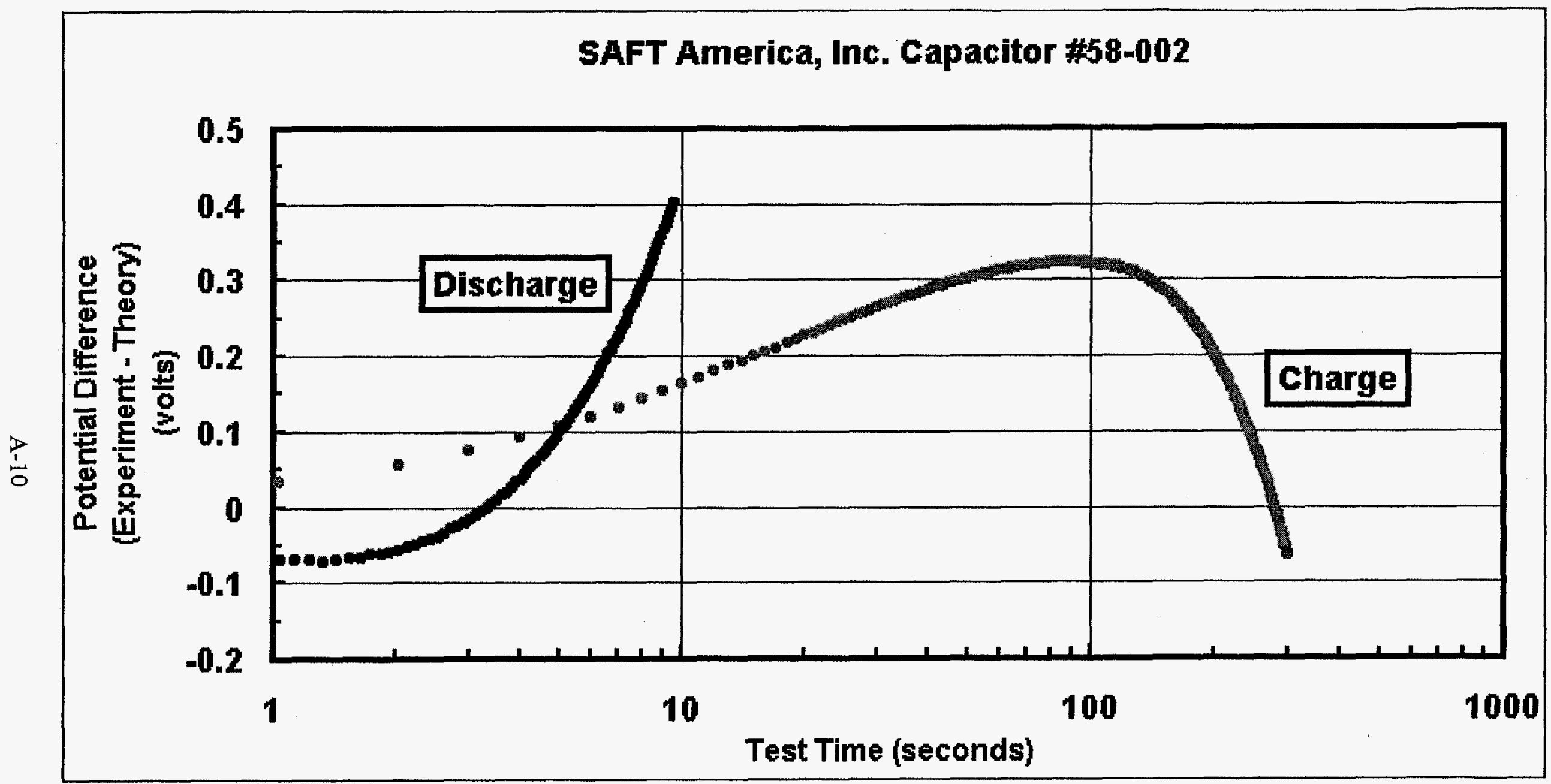

Figure A-8. Calculated potential difference (experimental-theoretical) as a function of test time for the $0.5 \mathrm{~A}$ constant-current charge and $12 \mathrm{~A}$ constant-current discharge test data shown in Figure A-7. 


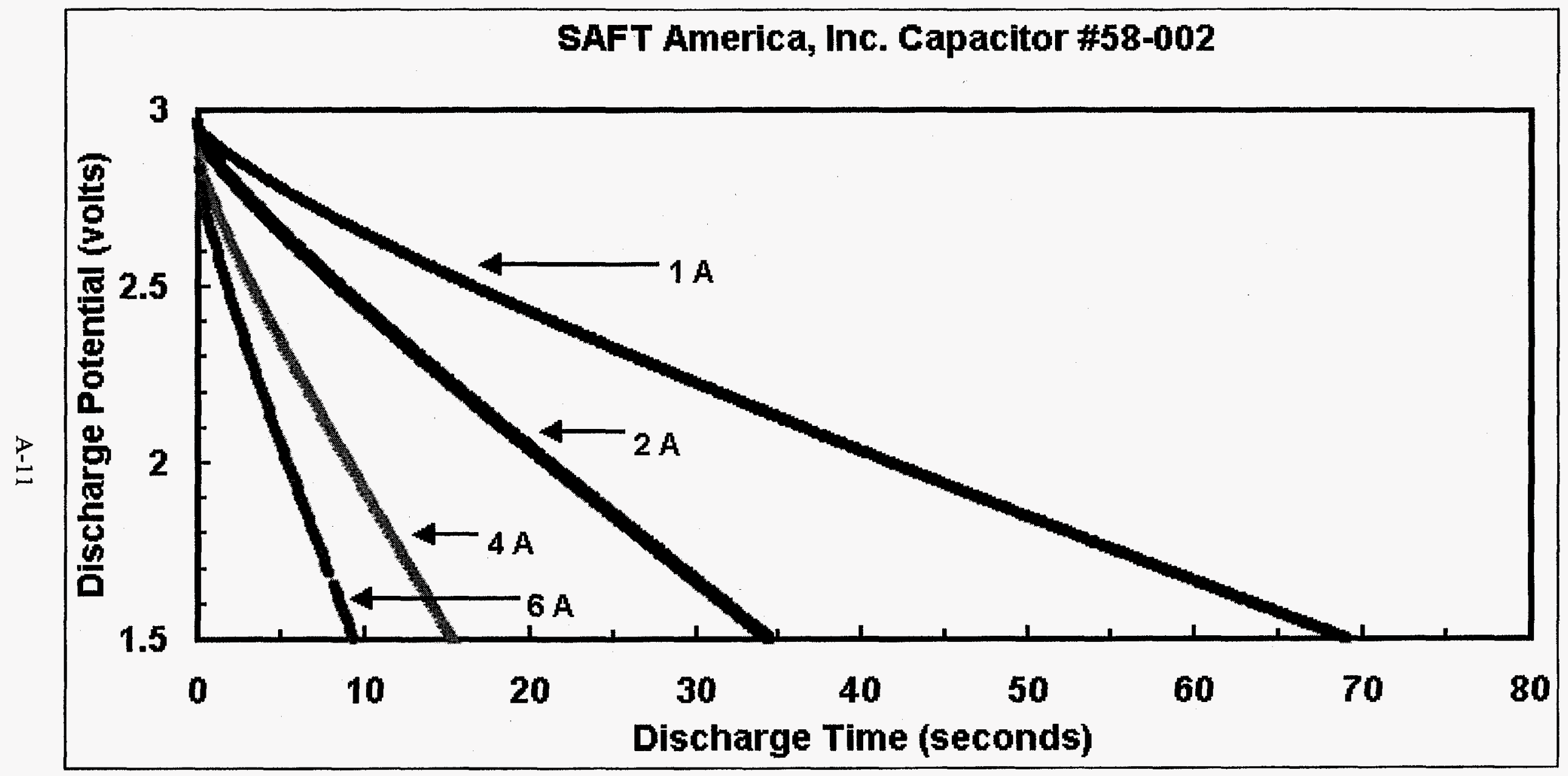

Figure A-9. Capacitor discharge potential for 3 to $1.5 \mathrm{~V}$ as a function of discharge time for constant-current tests that used 1, 2, 4, and $6 \mathrm{~A}$ constant-current discharges. All tests used a 0.5 A constant-current charge. 


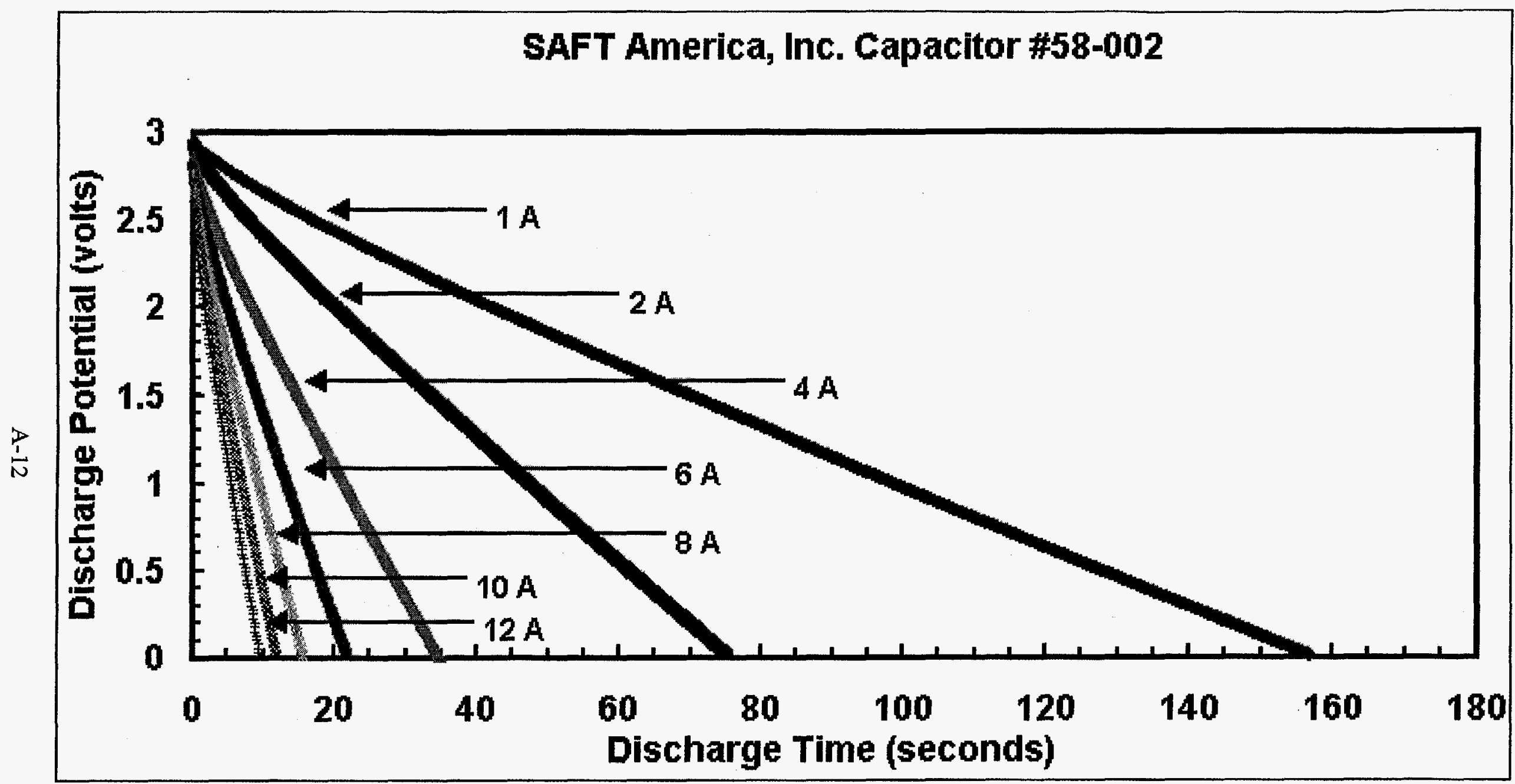

Figure A-10. Capacitor discharge potential for 3 to $0 \mathrm{~V}$ as a function of discharge time for constant-current tests that used $1,2,4,6,8,10$, and 12 A constant-current discharges. All tests used a 0.5 A constant-current charge. 


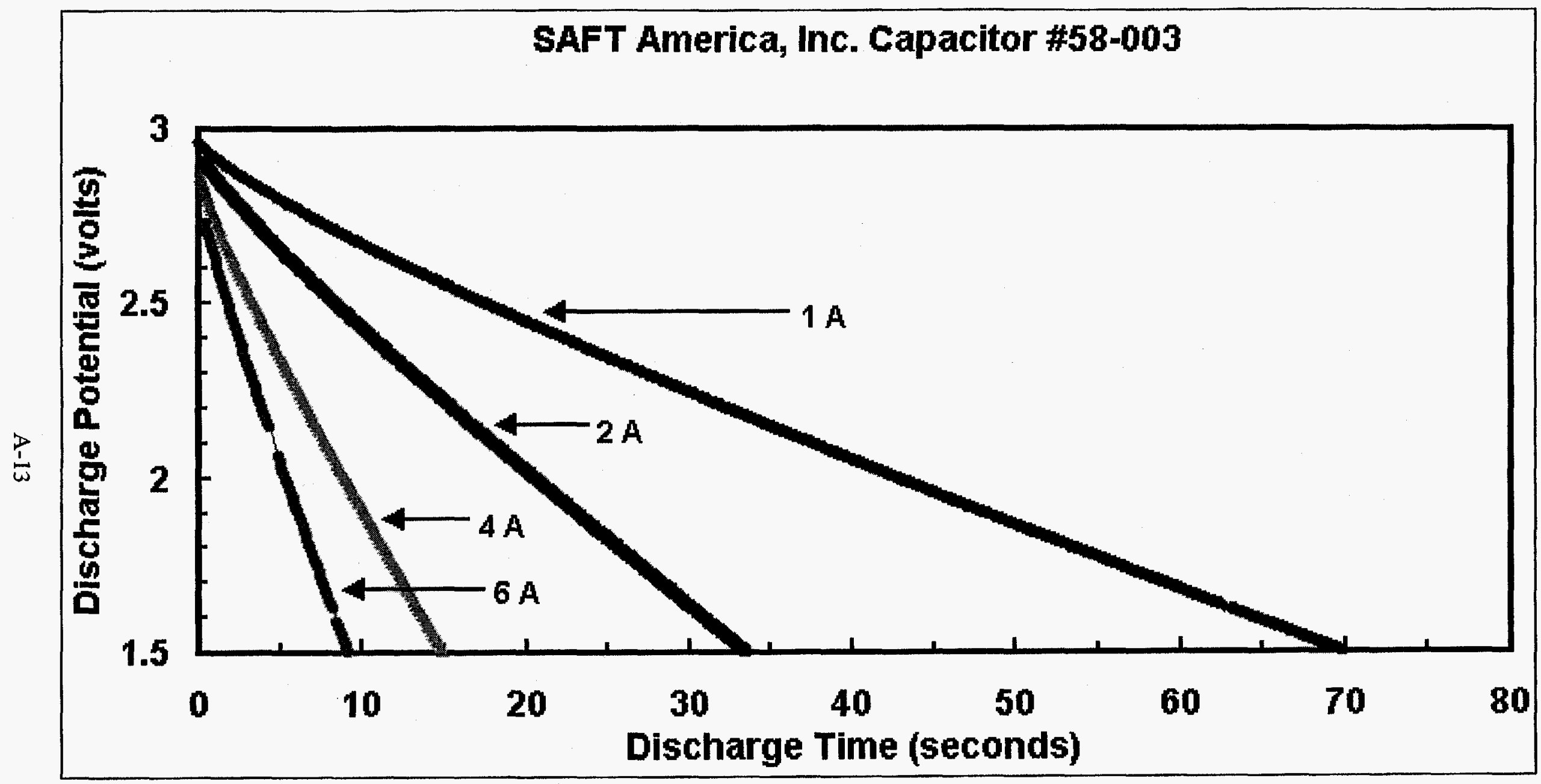

Figure A-11. Capacitor discharge potential for 3 to $1.5 \mathrm{~V}$ as a function of discharge time for constant-current tests that used 1,2, 4, and $6 \mathrm{~A}$ constant-current discharges. All tests used a 0.5 A constant-current charge. 


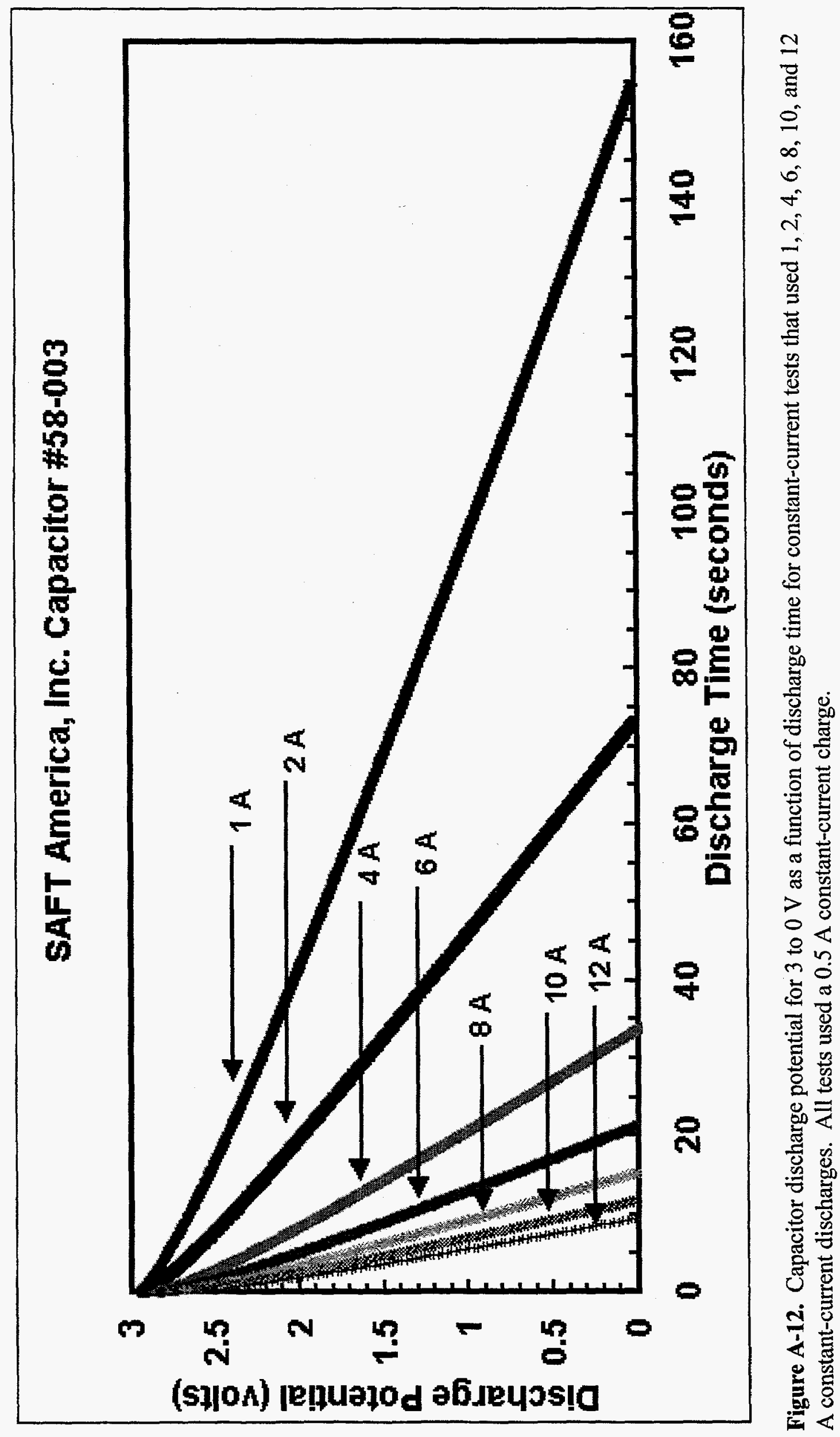




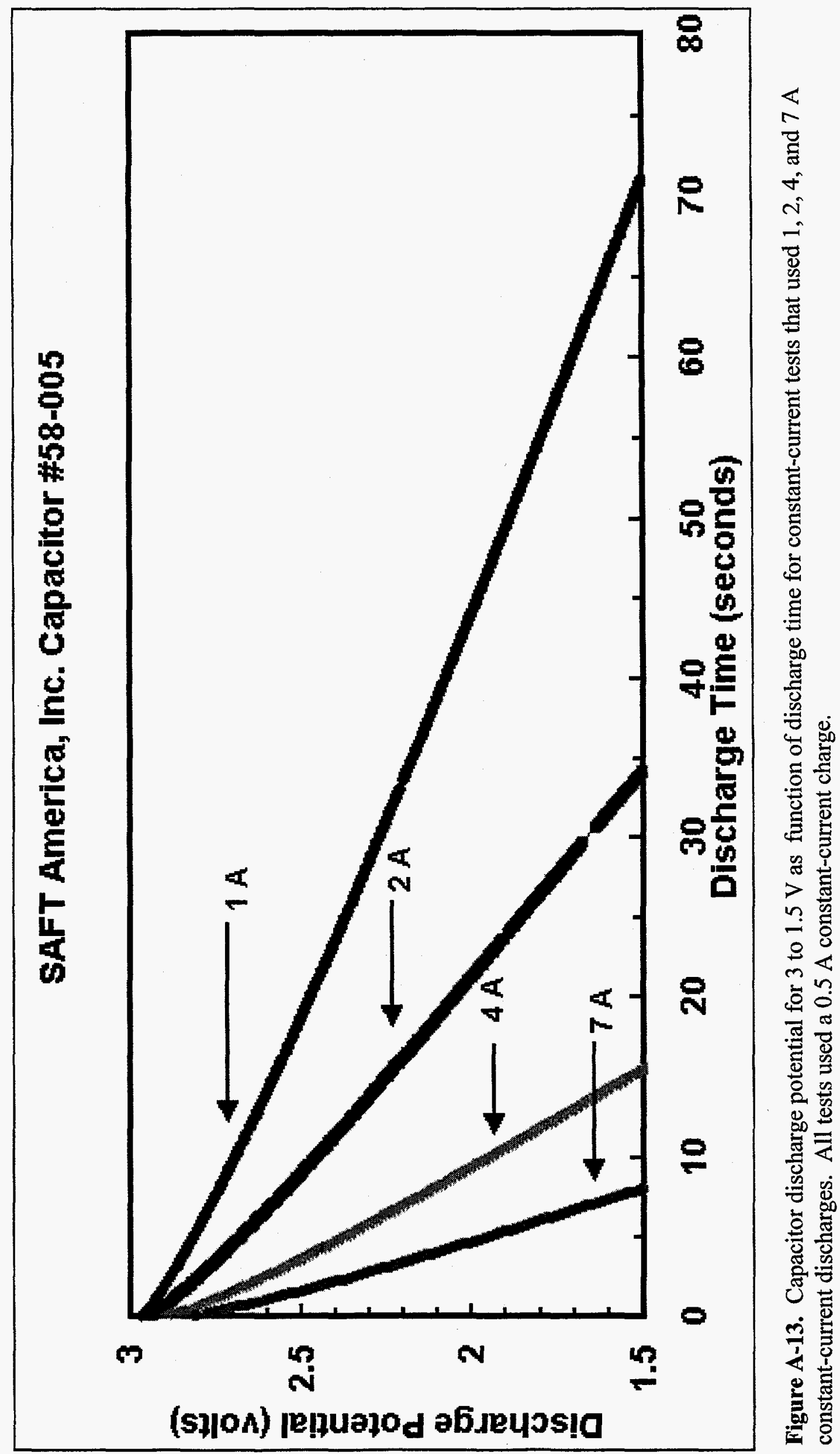




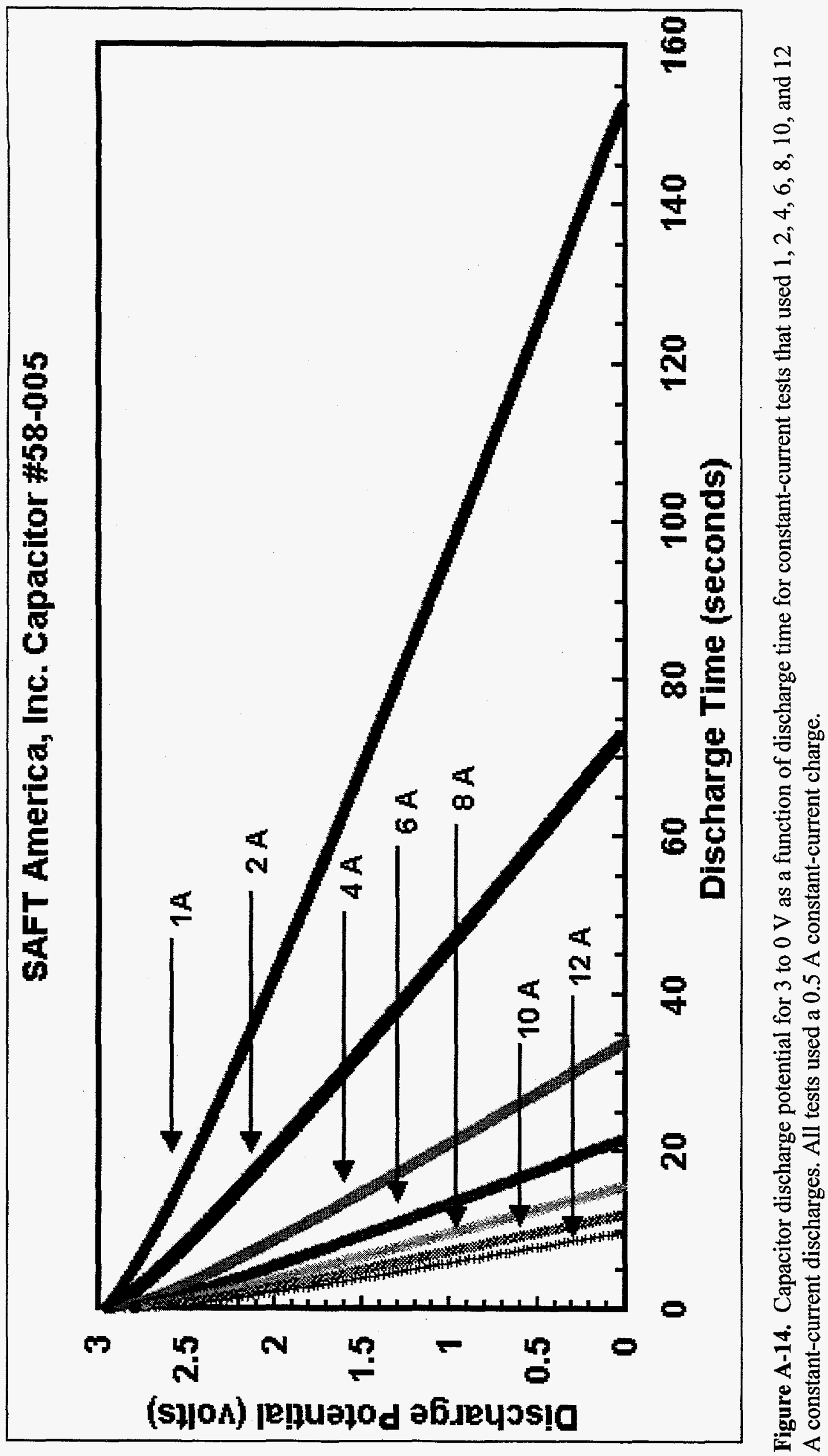




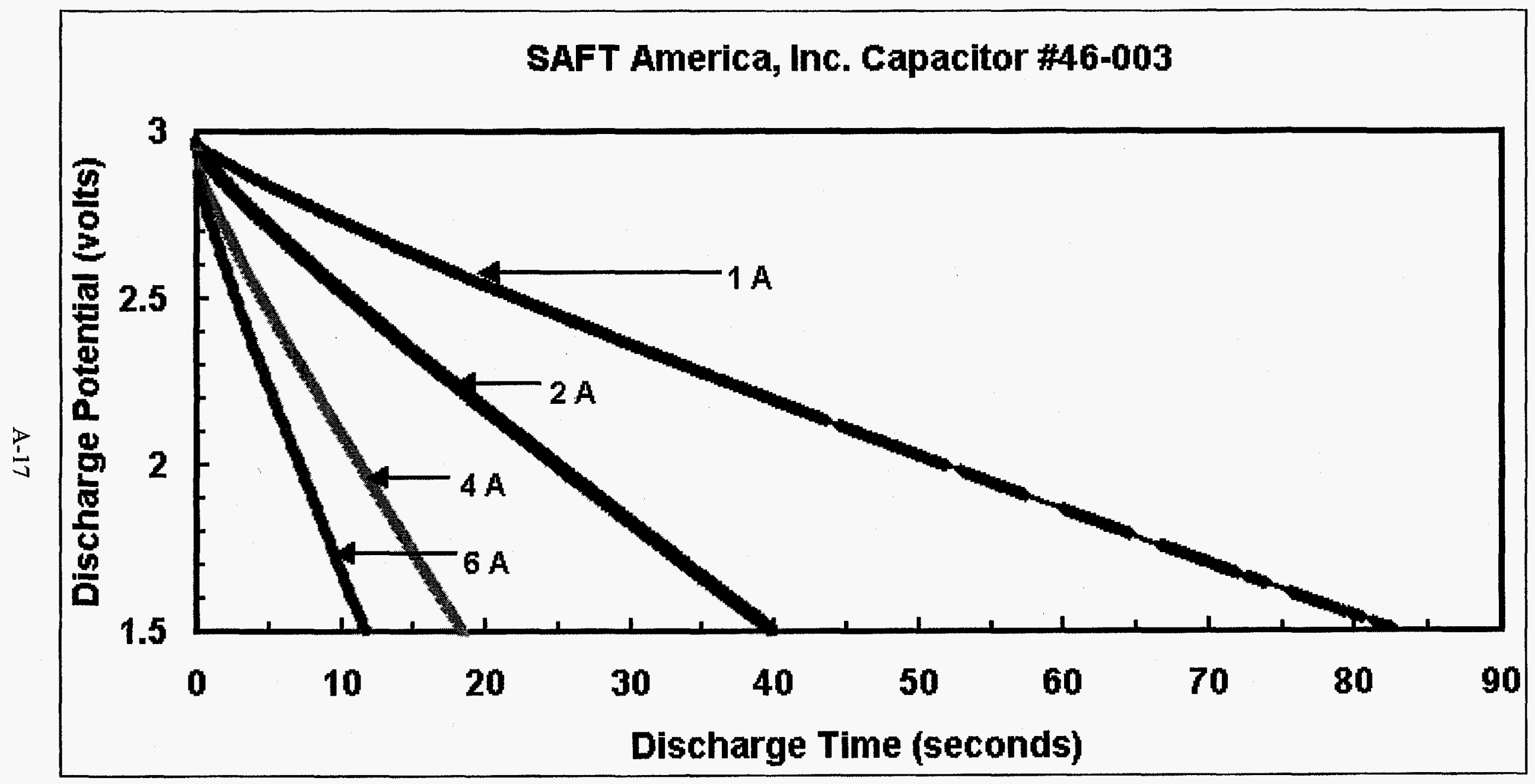

Figure A-15. Capacitor discharge potential for 3 to $1.5 \mathrm{~V}$ as a function of discharge time for constant-current tests that used $1,2,4$, and $6 \mathrm{~A}$ constant-current discharges. All tests used a 0.5 A constant-current charge. 


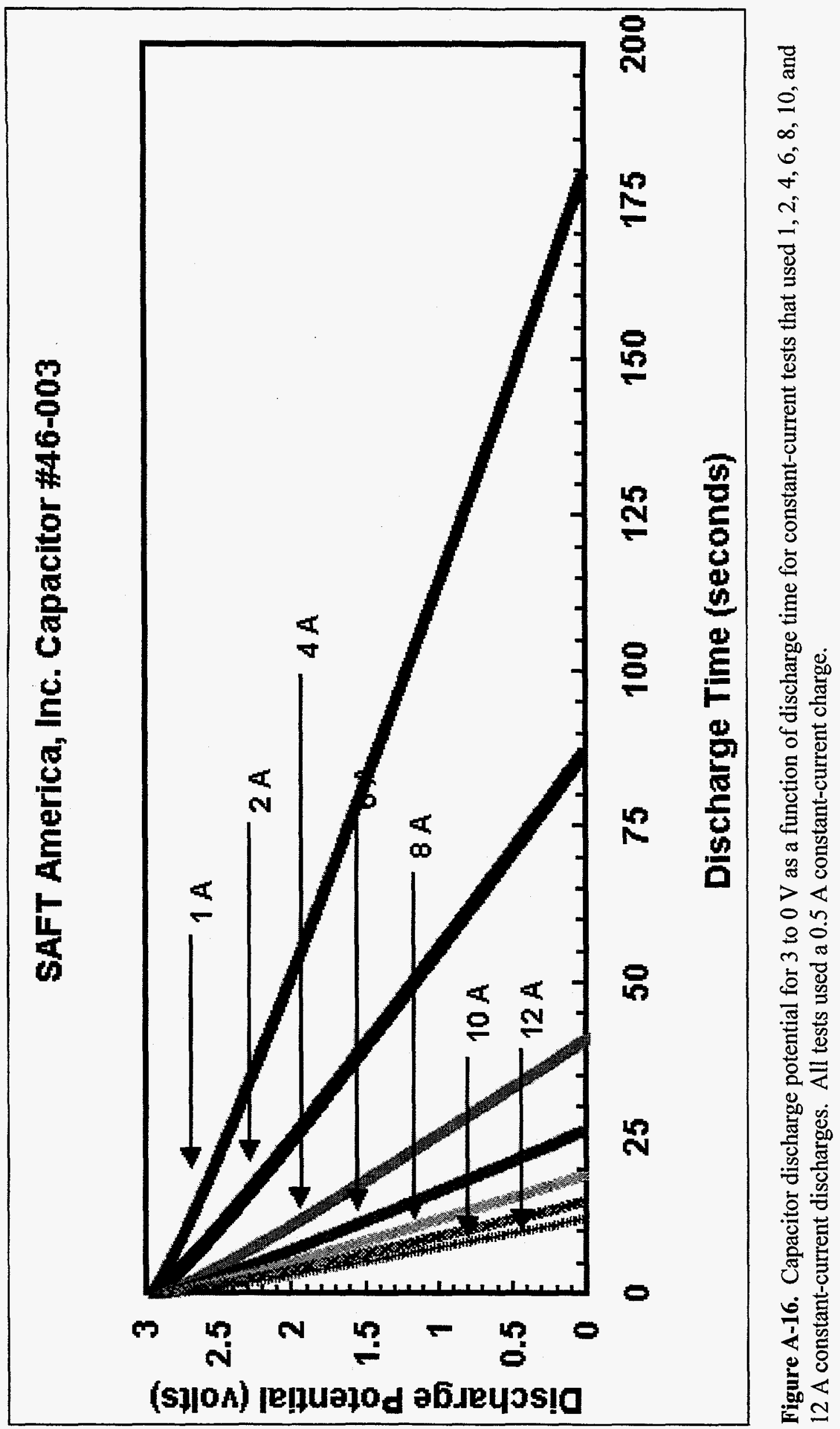




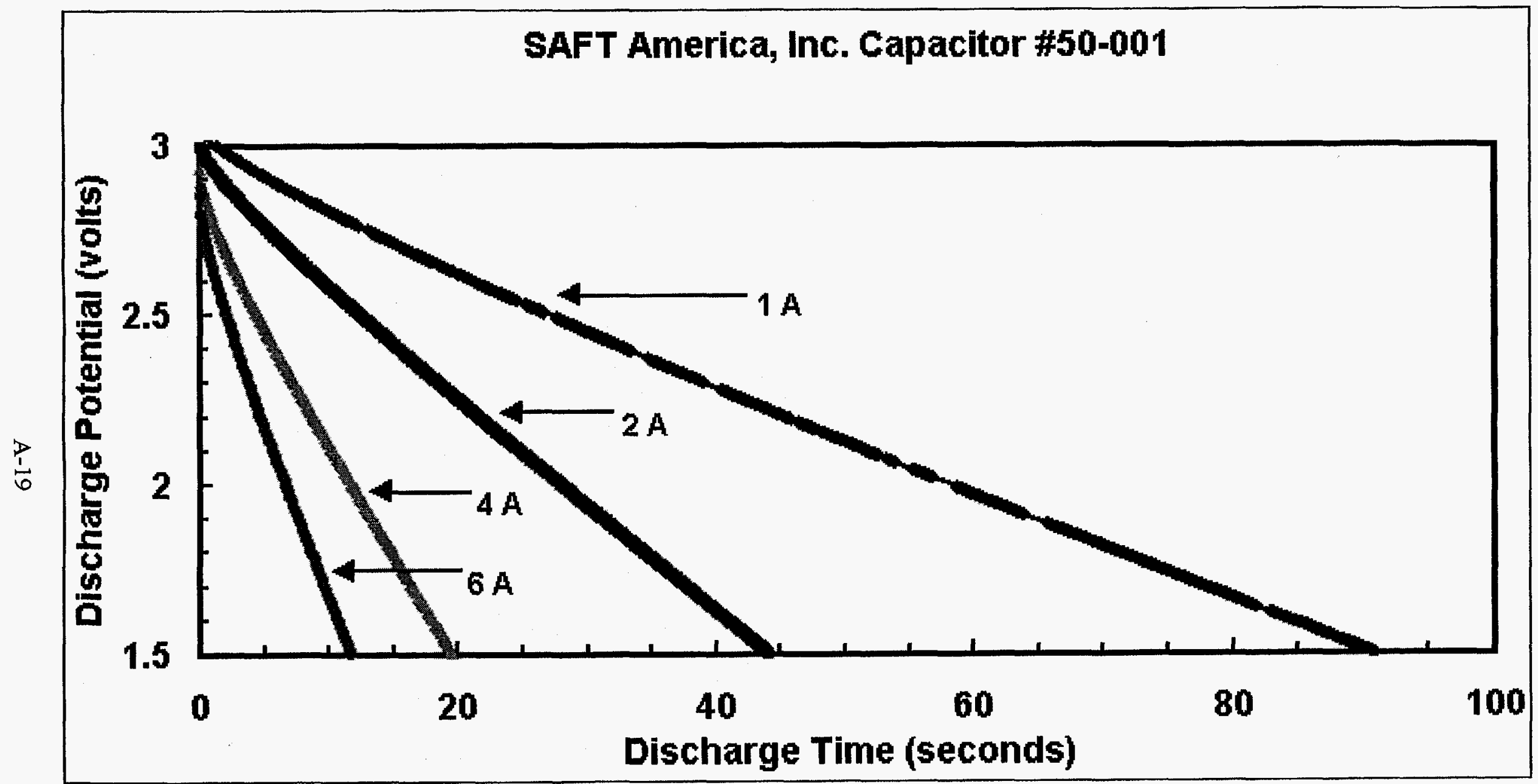

Figure A-17. Capacitor discharge potential for 3 to $1.5 \mathrm{~V}$ as a function of discharge time for constant-current tests that used 1, 2, 4, and $6 \mathrm{~A}$ constant-current discharges. All tests used a $0.5 \mathrm{~A}$ constant-current charge. 


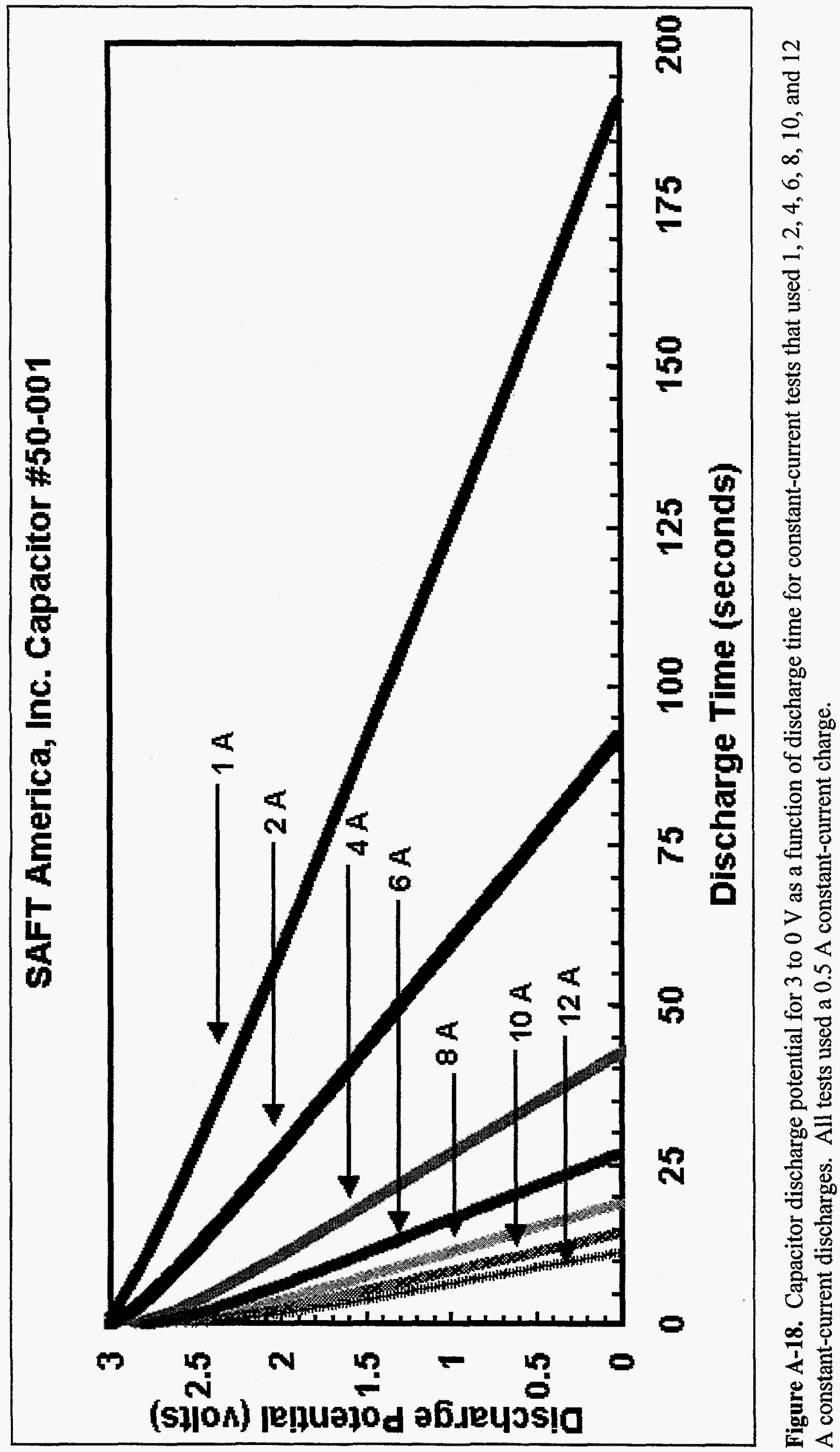




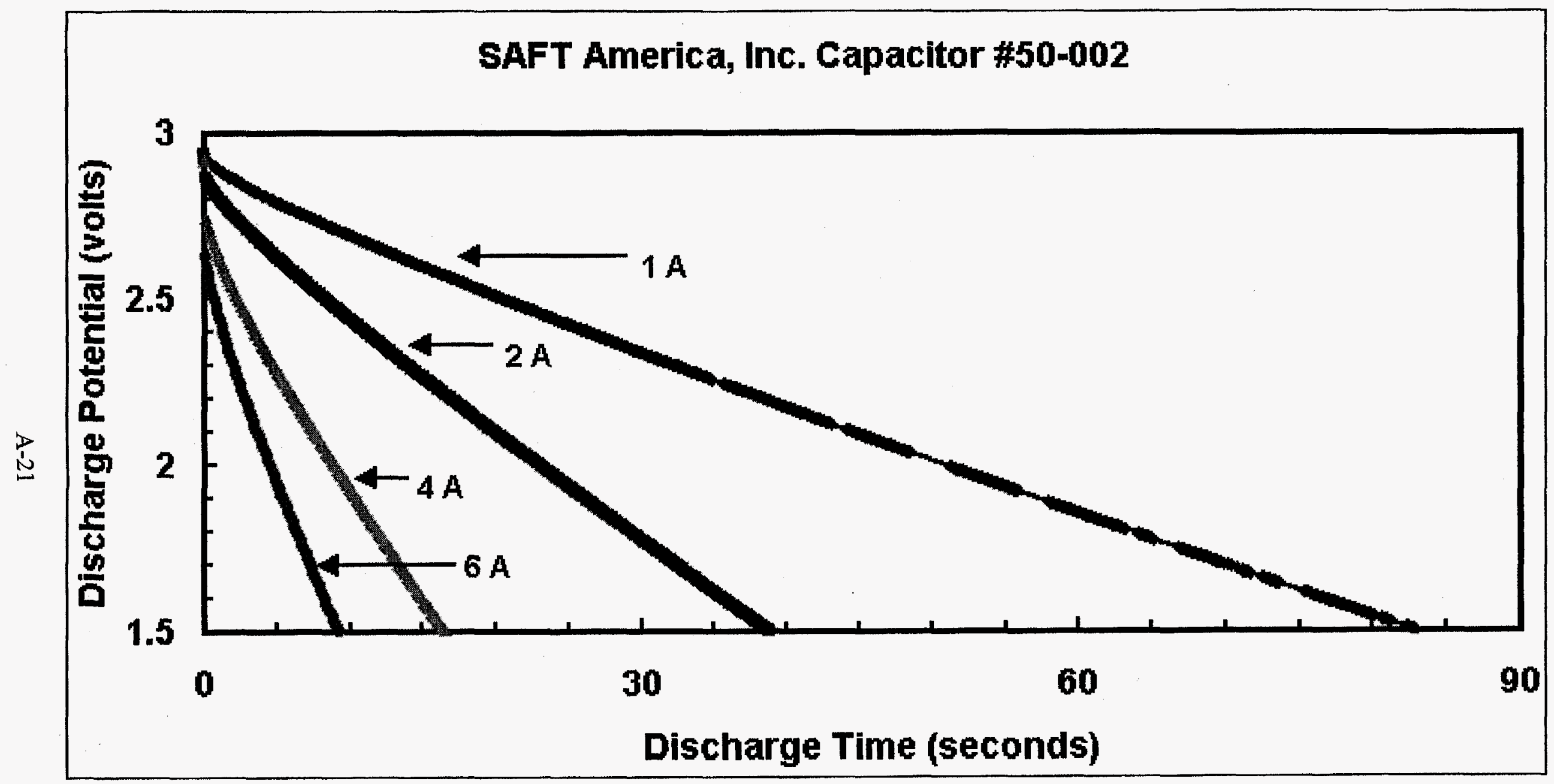

Figure A-19. Capacitor discharge potential for 3 to $1.5 \mathrm{~V}$ as a function of discharge time for constant-current tests that used 1, 2, 4, and $6 \mathrm{~A}$ constant-current discharges. All tests used a 0.5 A constant-current charge. 


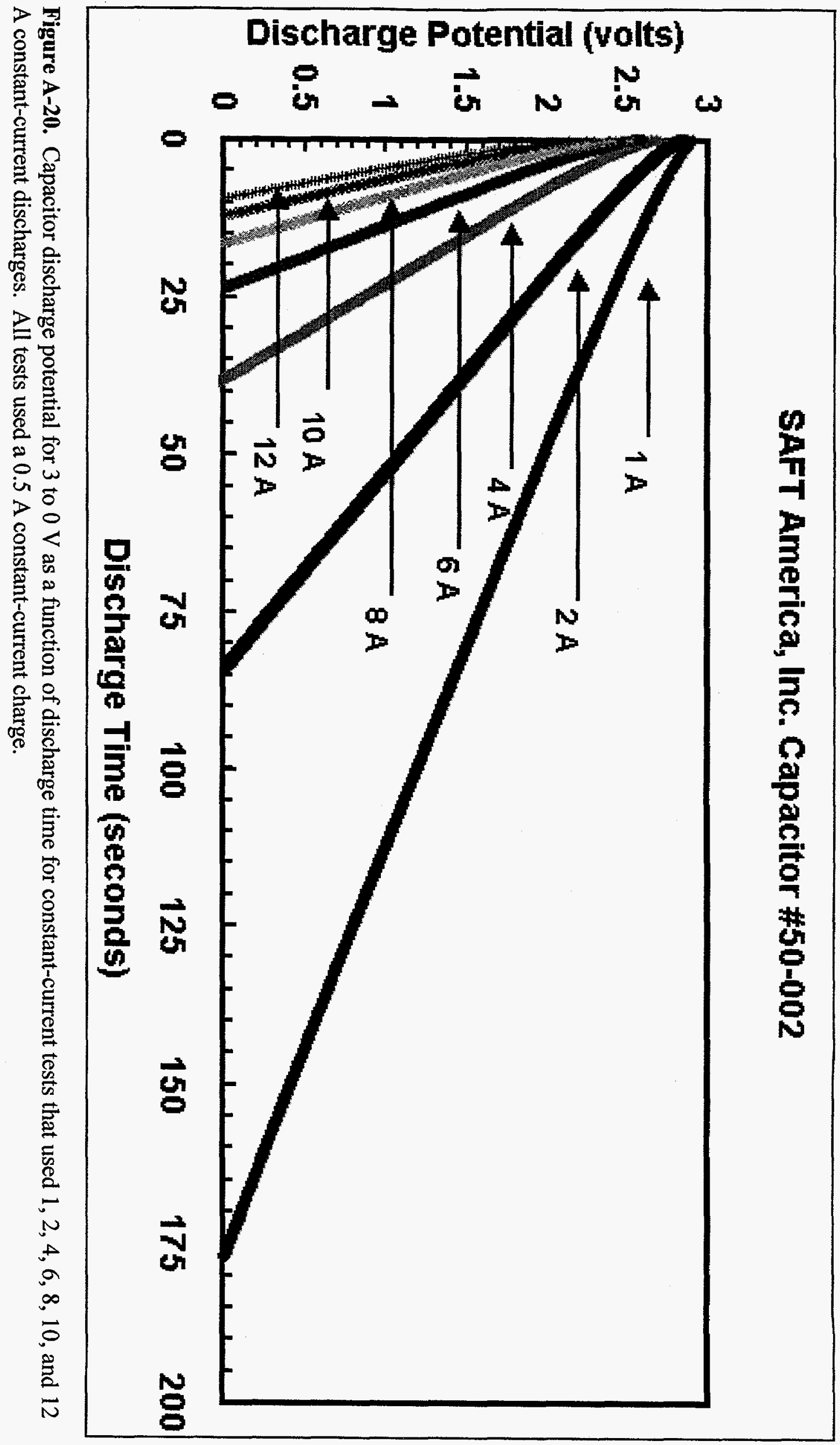




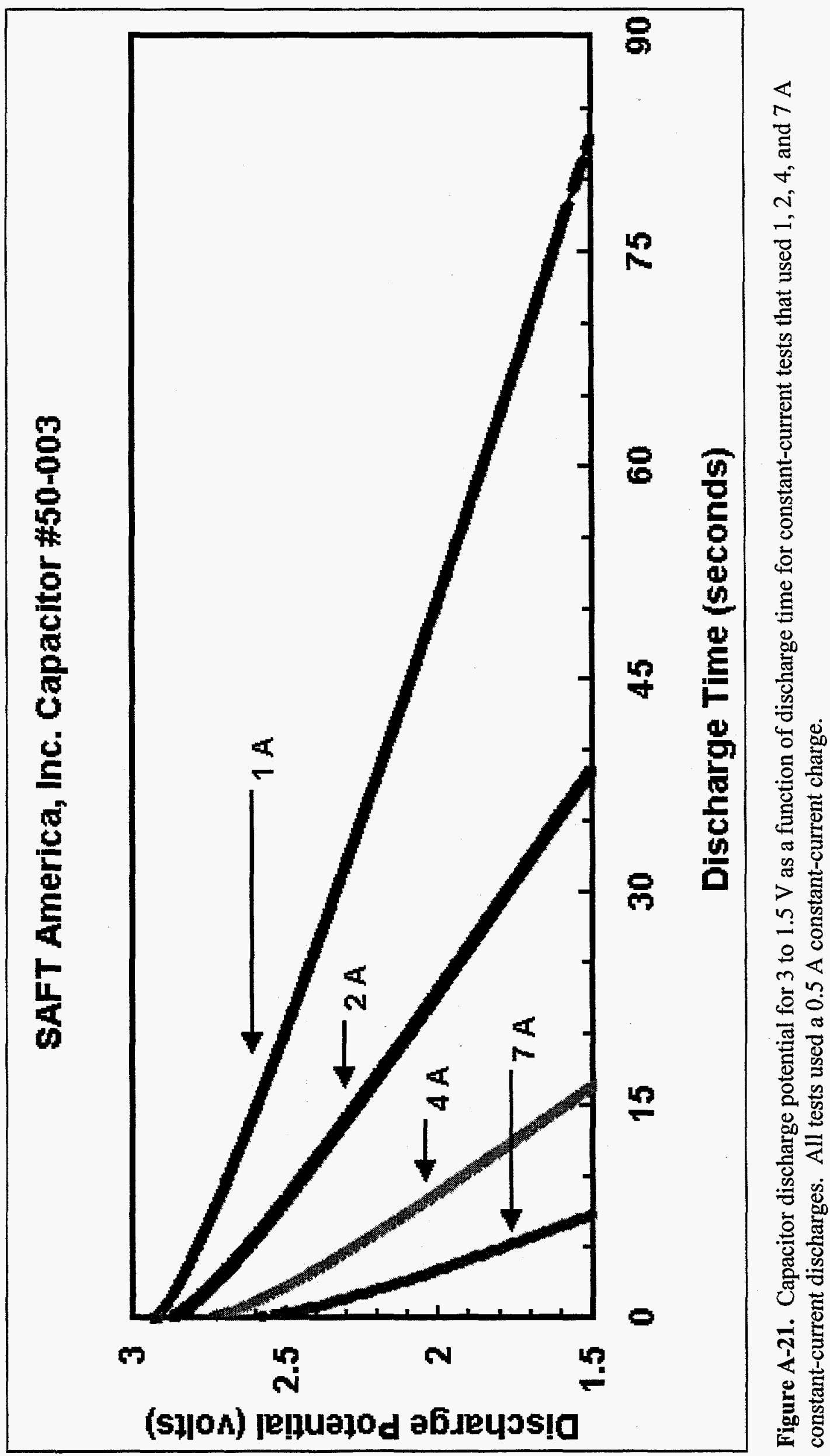




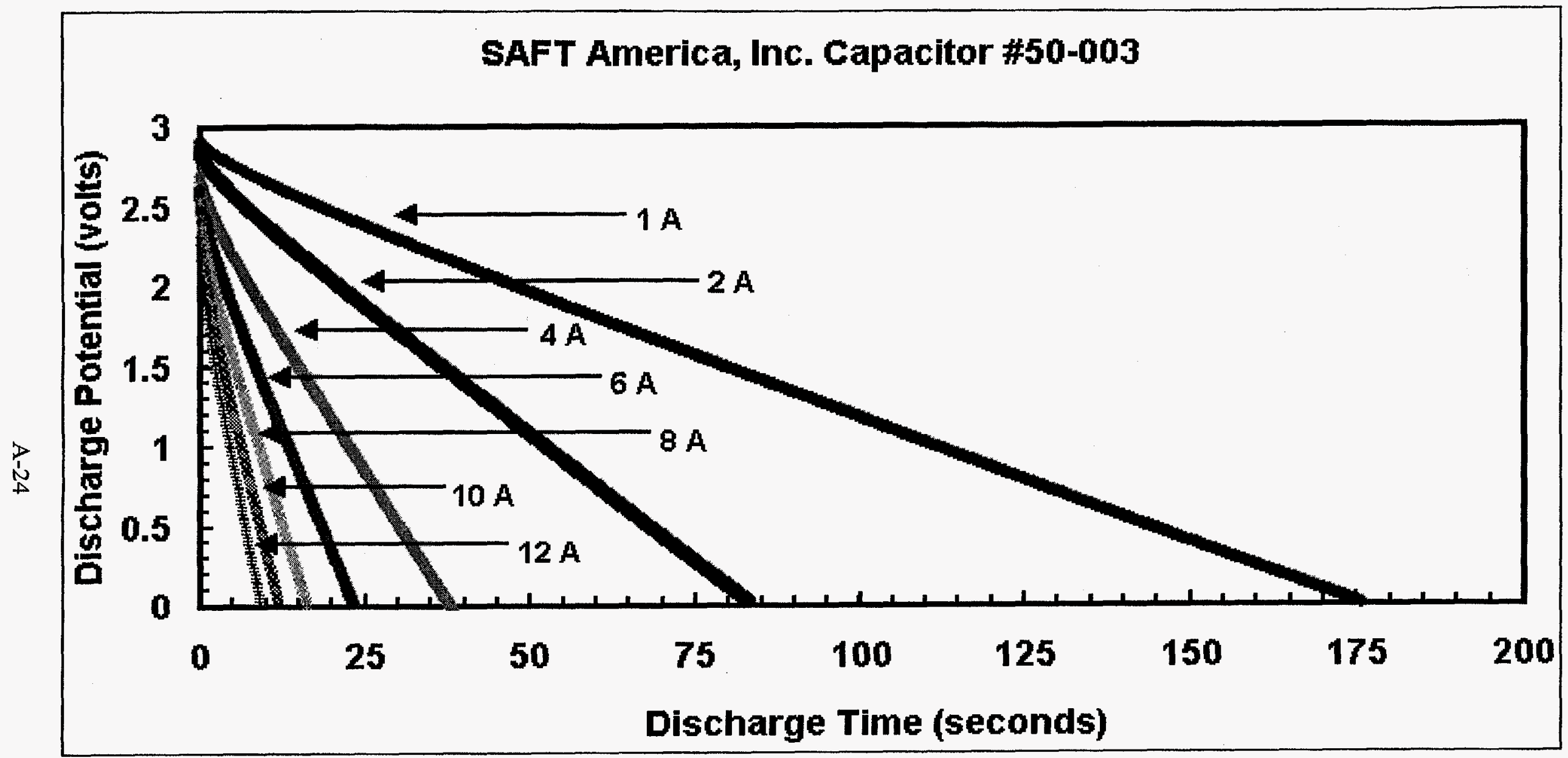

Figure A-22. Capacitor discharge potential for 3 to $0 \mathrm{~V}$ as a function of discharge time for constant-current tests that used 1,2, 4,6,8, 10, and 12 A constant-current discharges. All tests used a $0.5 \mathrm{~A}$ constant-current charge. 


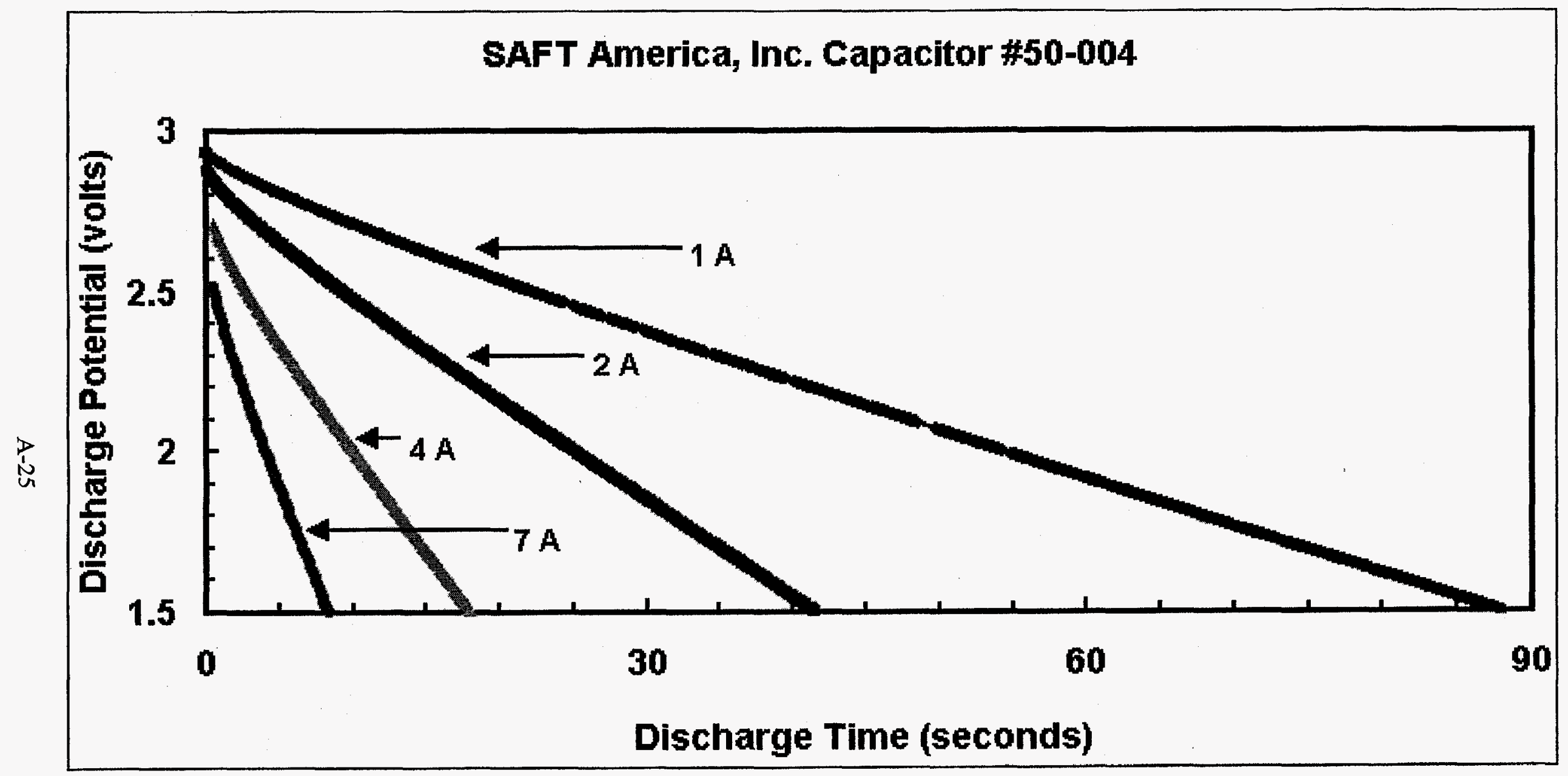

Figure A-23. Capacitor discharge potential for 3 to $1.5 \mathrm{~V}$ as a function of discharge time for constant-current tests that used $1,2,4$, and $7 \mathrm{~A}$ constant-current discharges. All tests used a 0.5 A constant-current charge. 


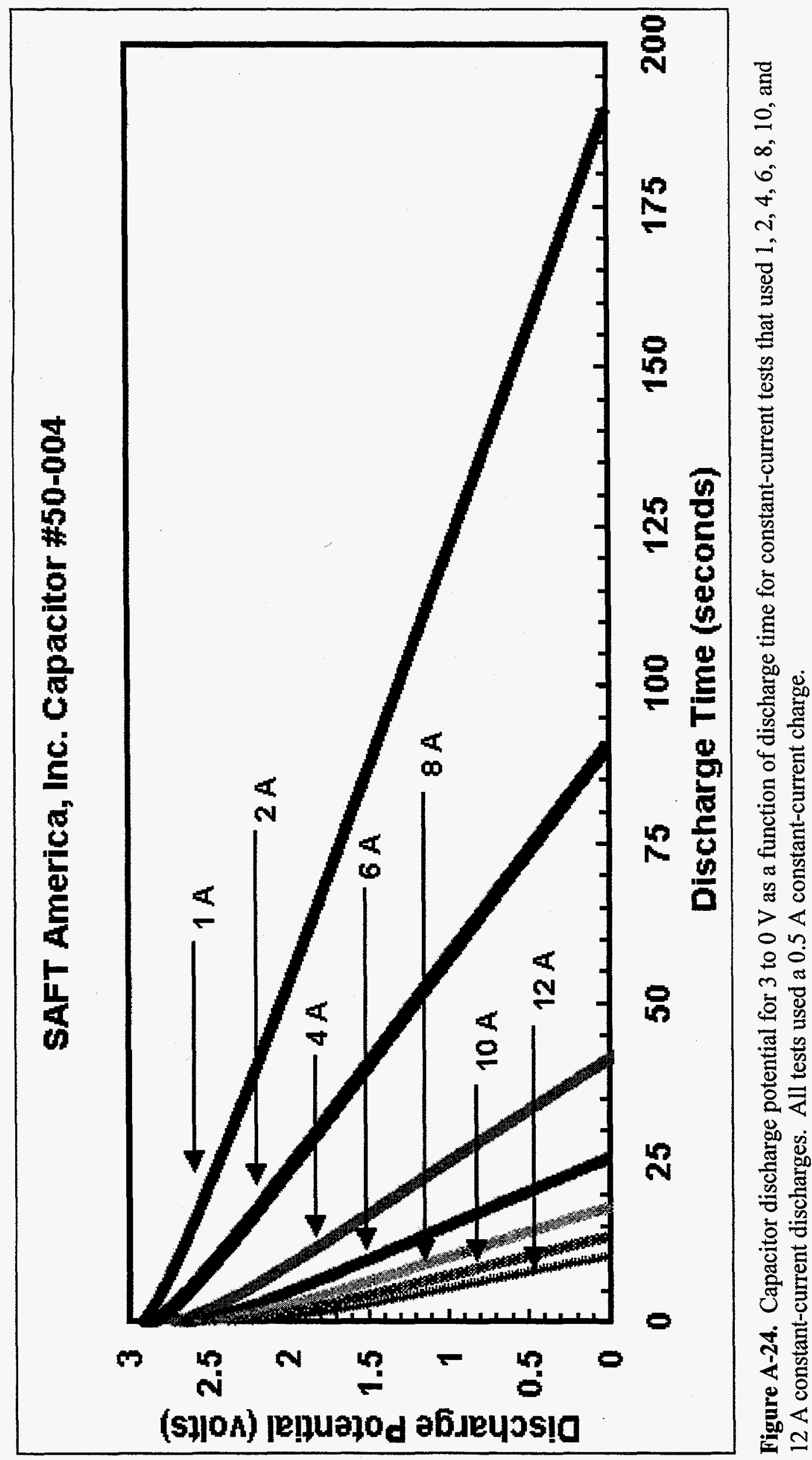




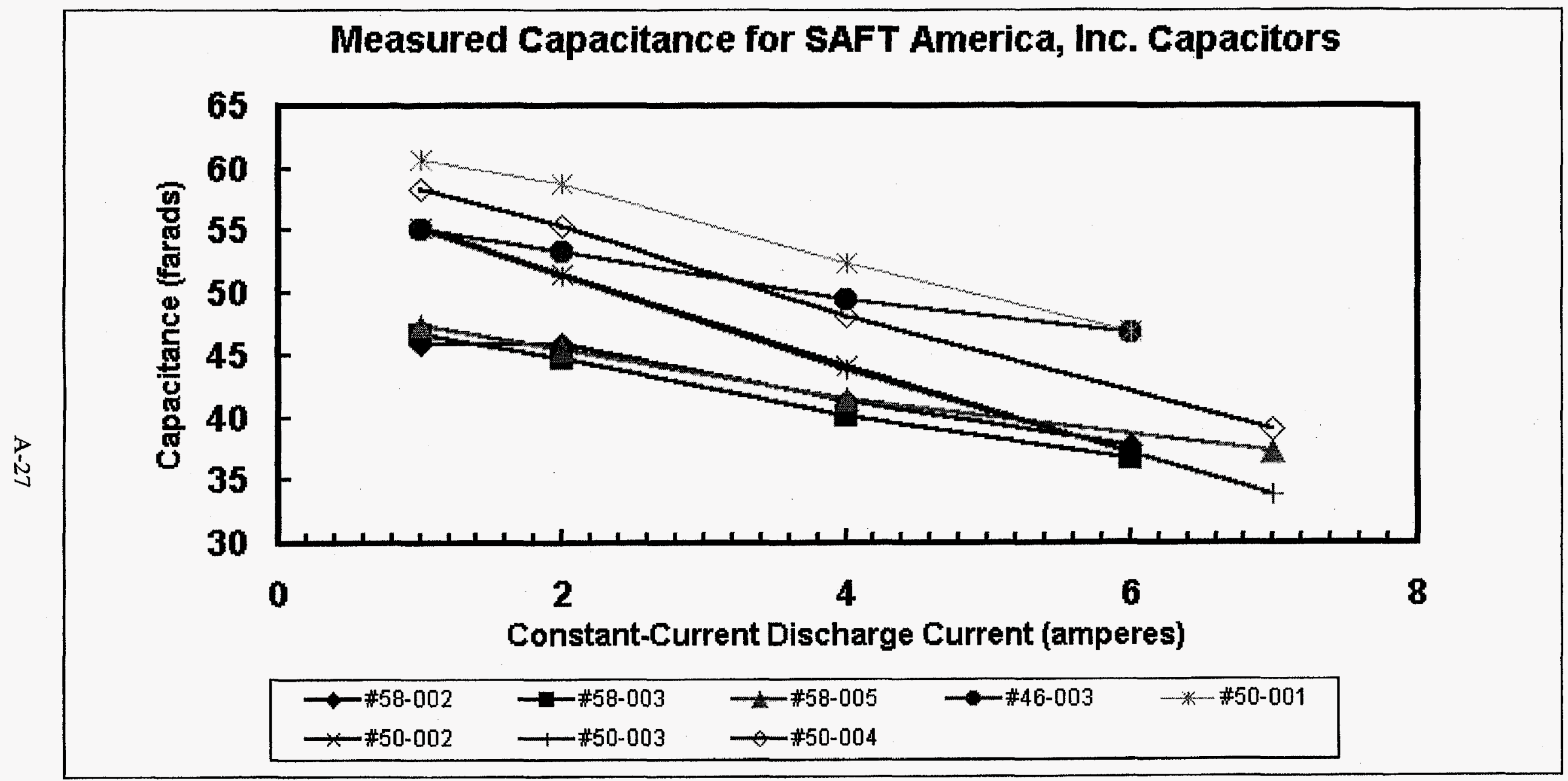

Figure A-25. Measured capacitance determined from constant-current tests over the voltage range of 3 to $1.5 \mathrm{~V}$ as a function of constant-current discharge current for the eight SAFT America, Inc. capacitors. 


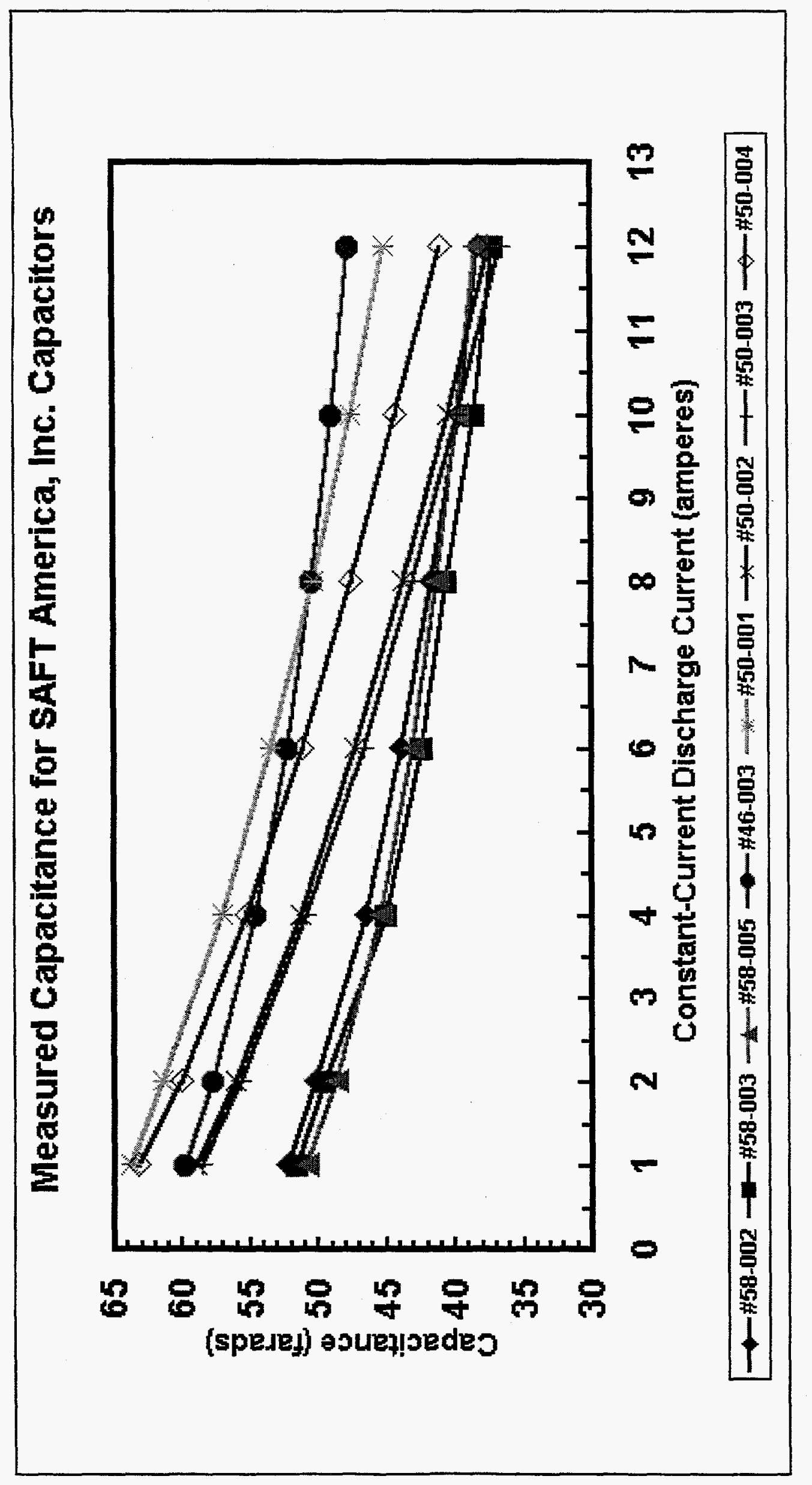

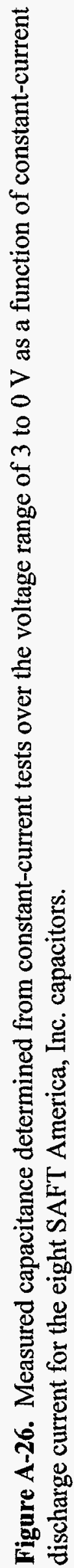




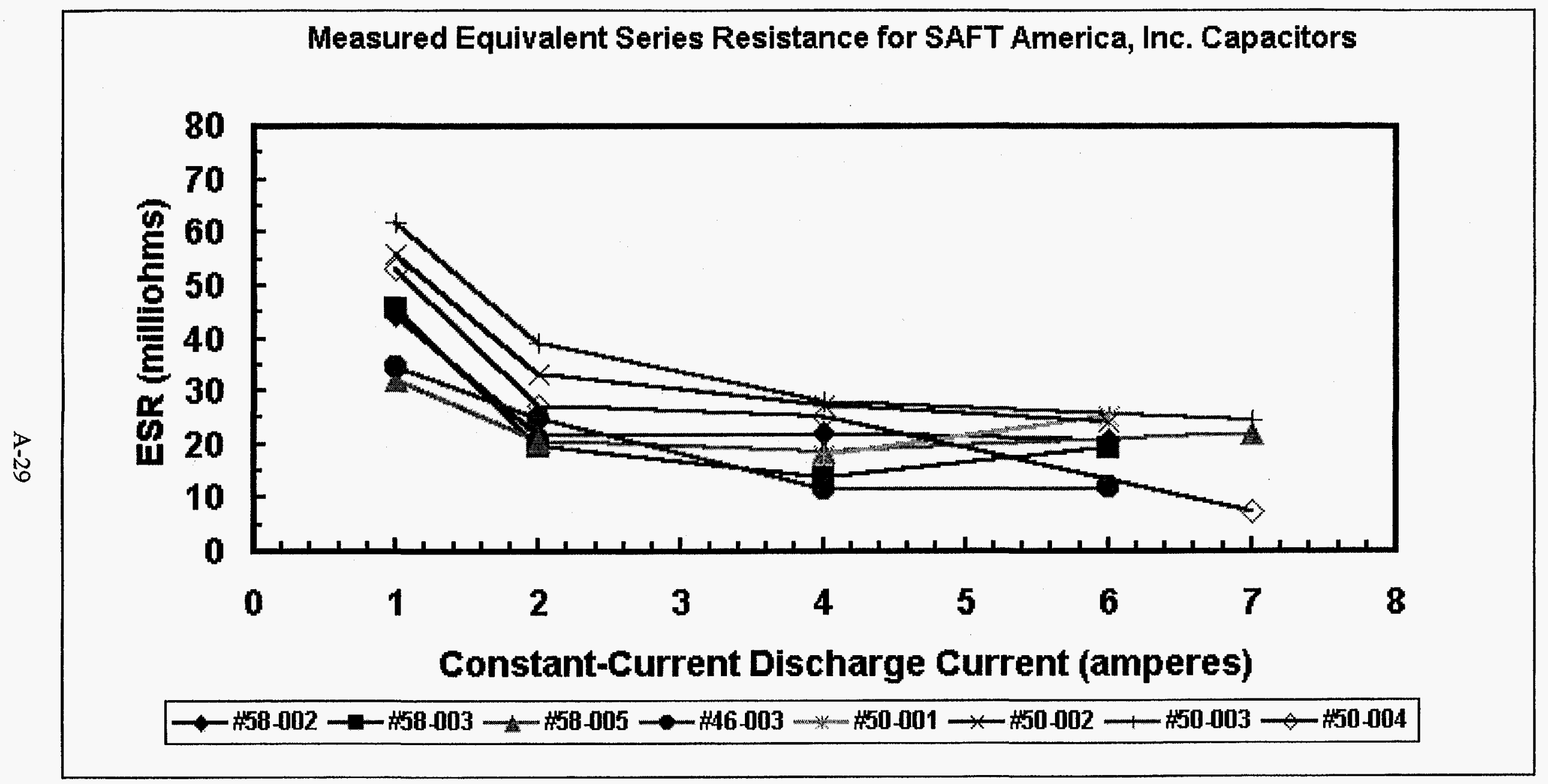

Figure A-27. Measured Equivalent Series Resistance (ESR) determined from constant-current tests over the voltage range of 3 to $1.5 \mathrm{~V}$ as a function of constant-current discharge current for the eight SAFT America, Inc. capacitors. 


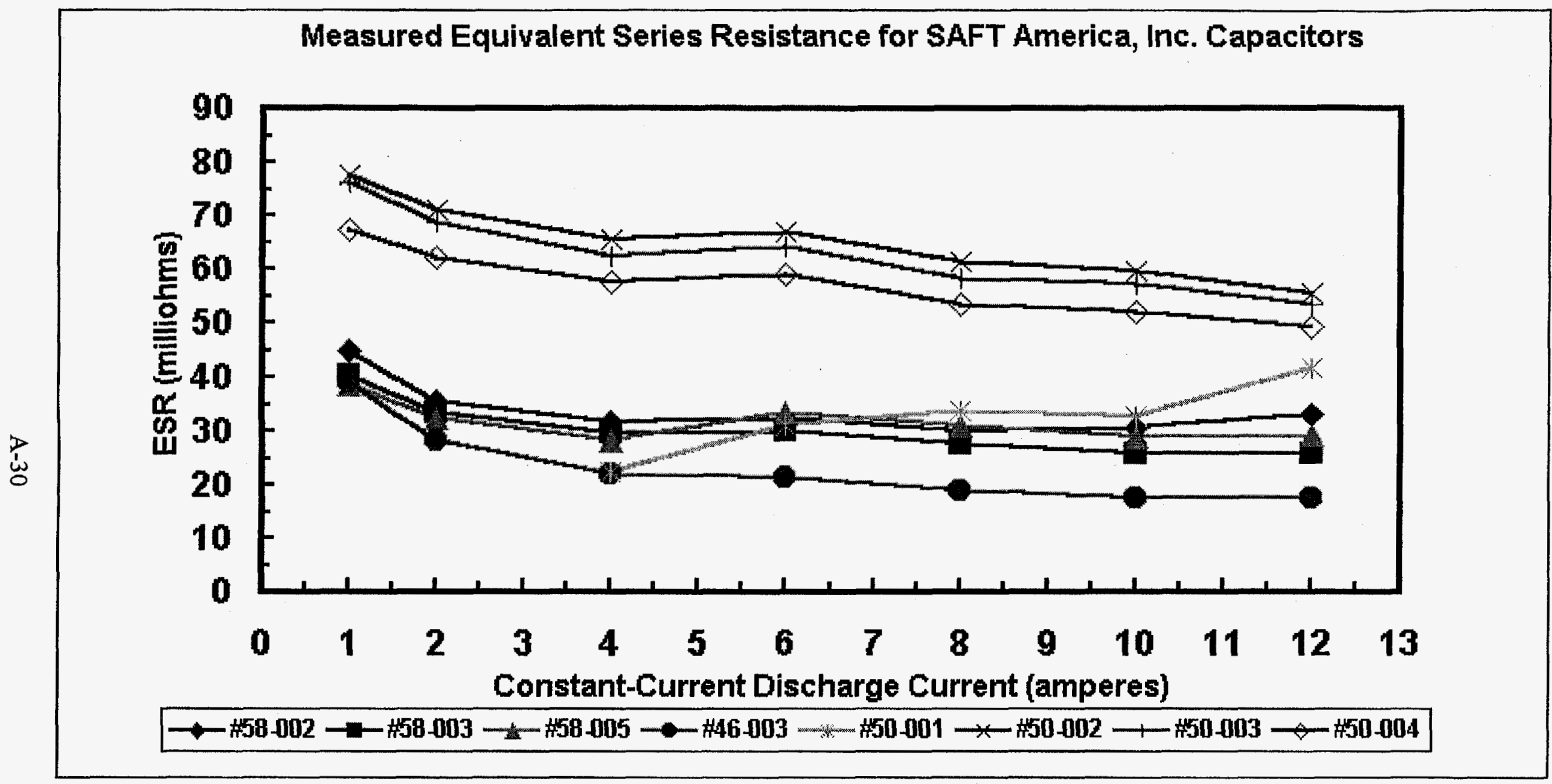

Figure A-28. Measured capacitance determined from constant-current tests over the voltage range of 3 to $0 \mathrm{~V}$ as a function of constant-current discharge current for the eight SAFT America, Inc. capacitors. 


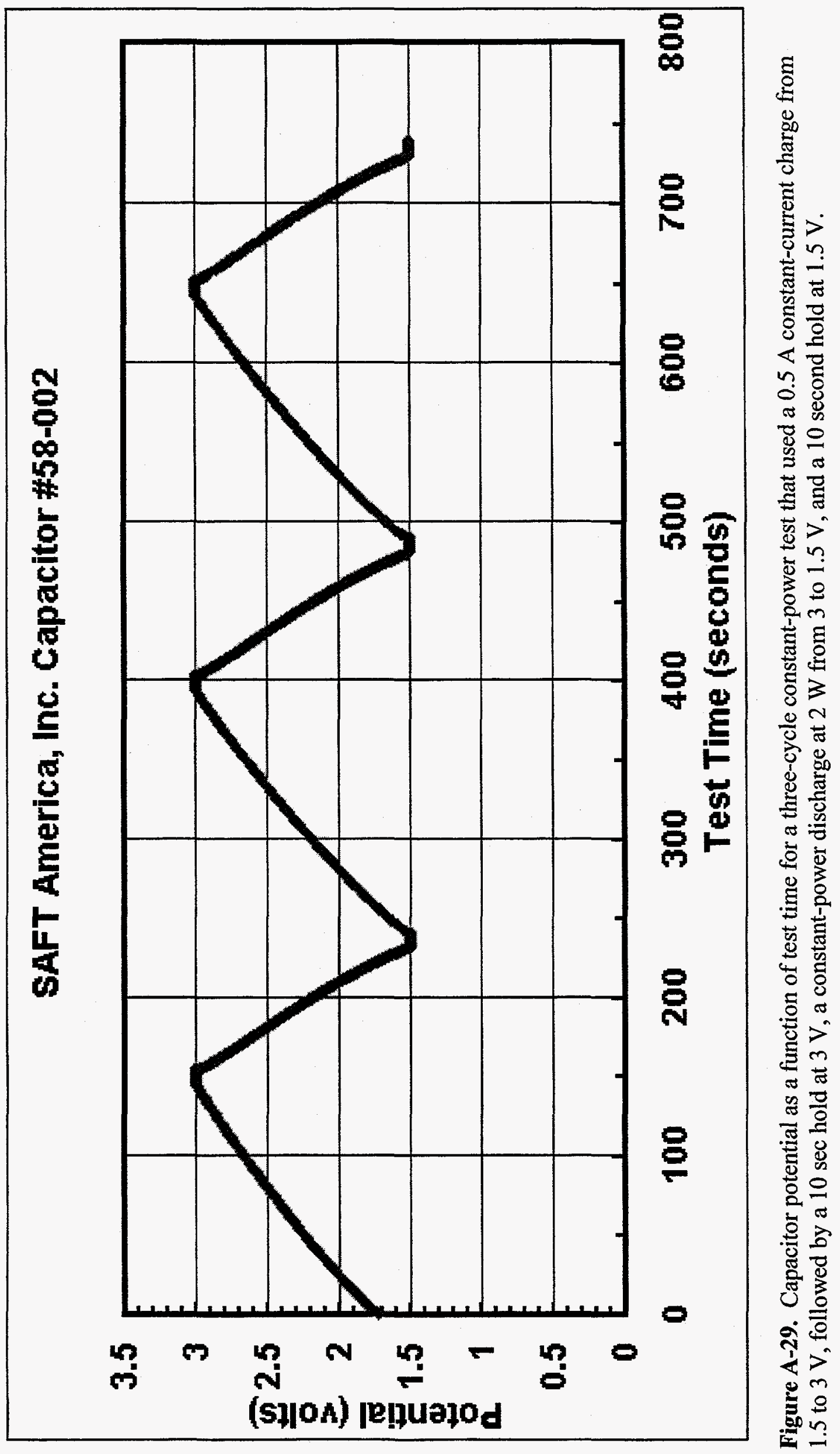




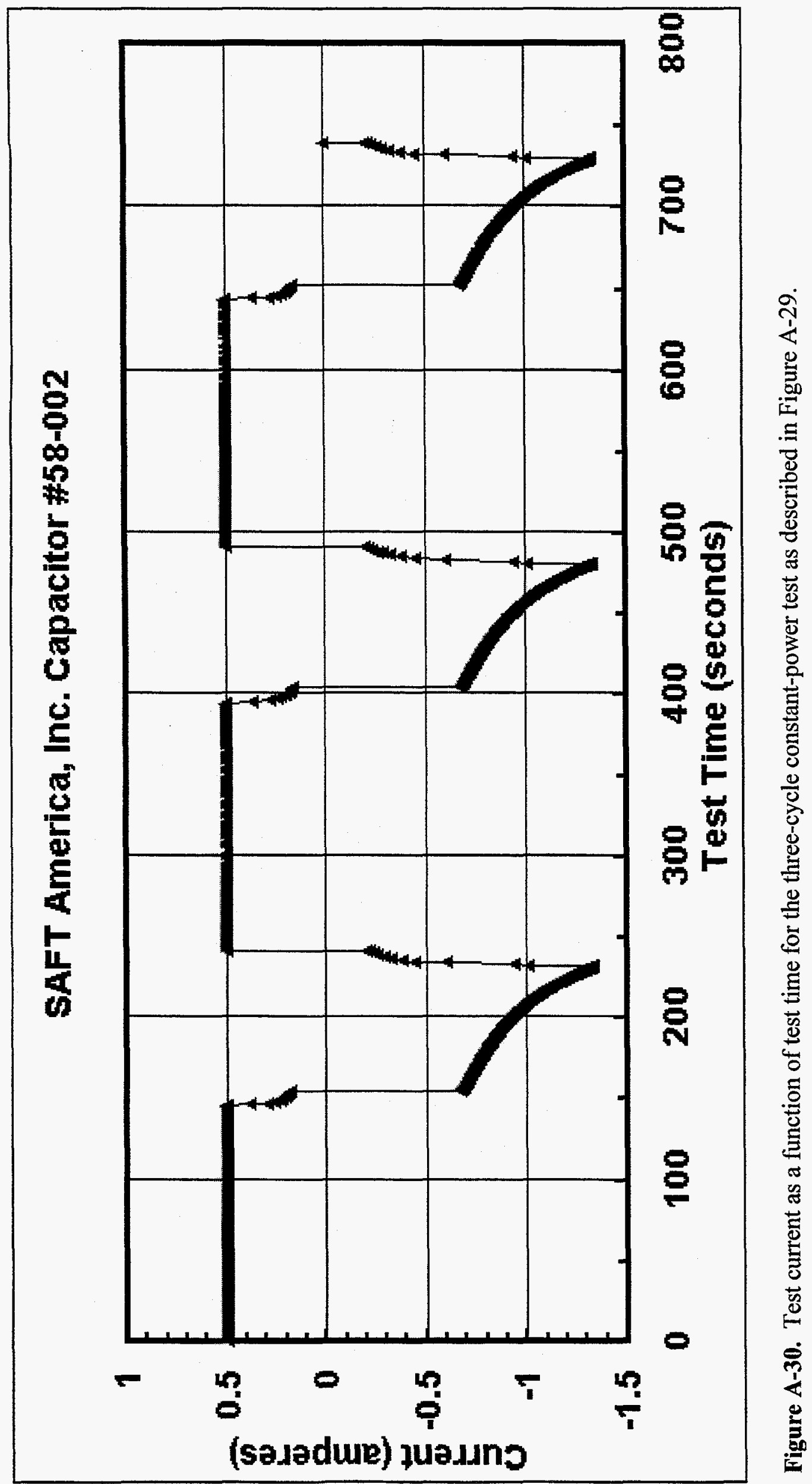




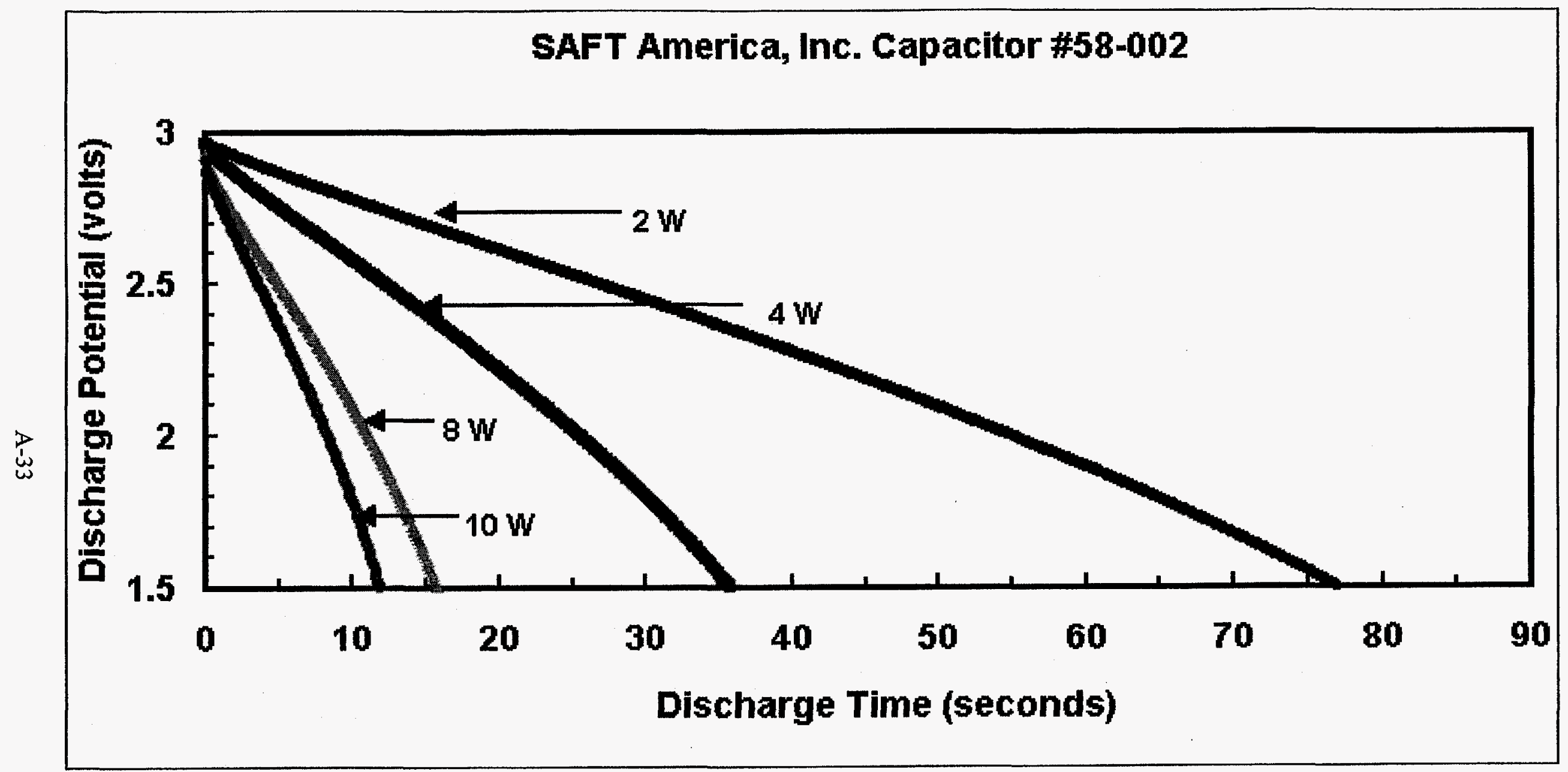

Figure A-31. Discharge potential as a function of discharge time for constant-power discharge tests at 2, 4, 8, and $10 \mathrm{~W}$. 


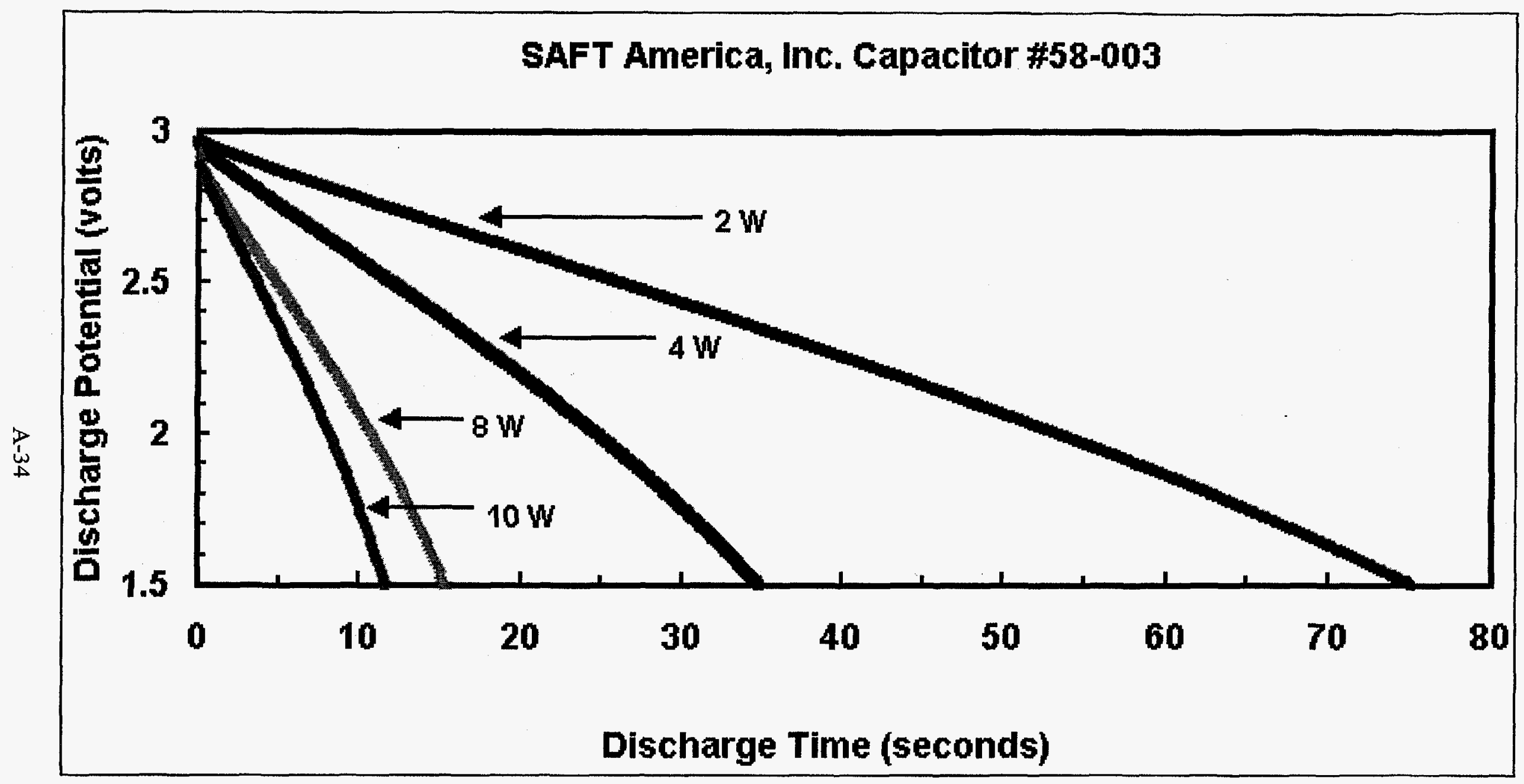

Figure A-32. Discharge potential as a function of discharge time for constant-power discharge tests at 2, 4, 8, and $10 \mathrm{~W}$. 


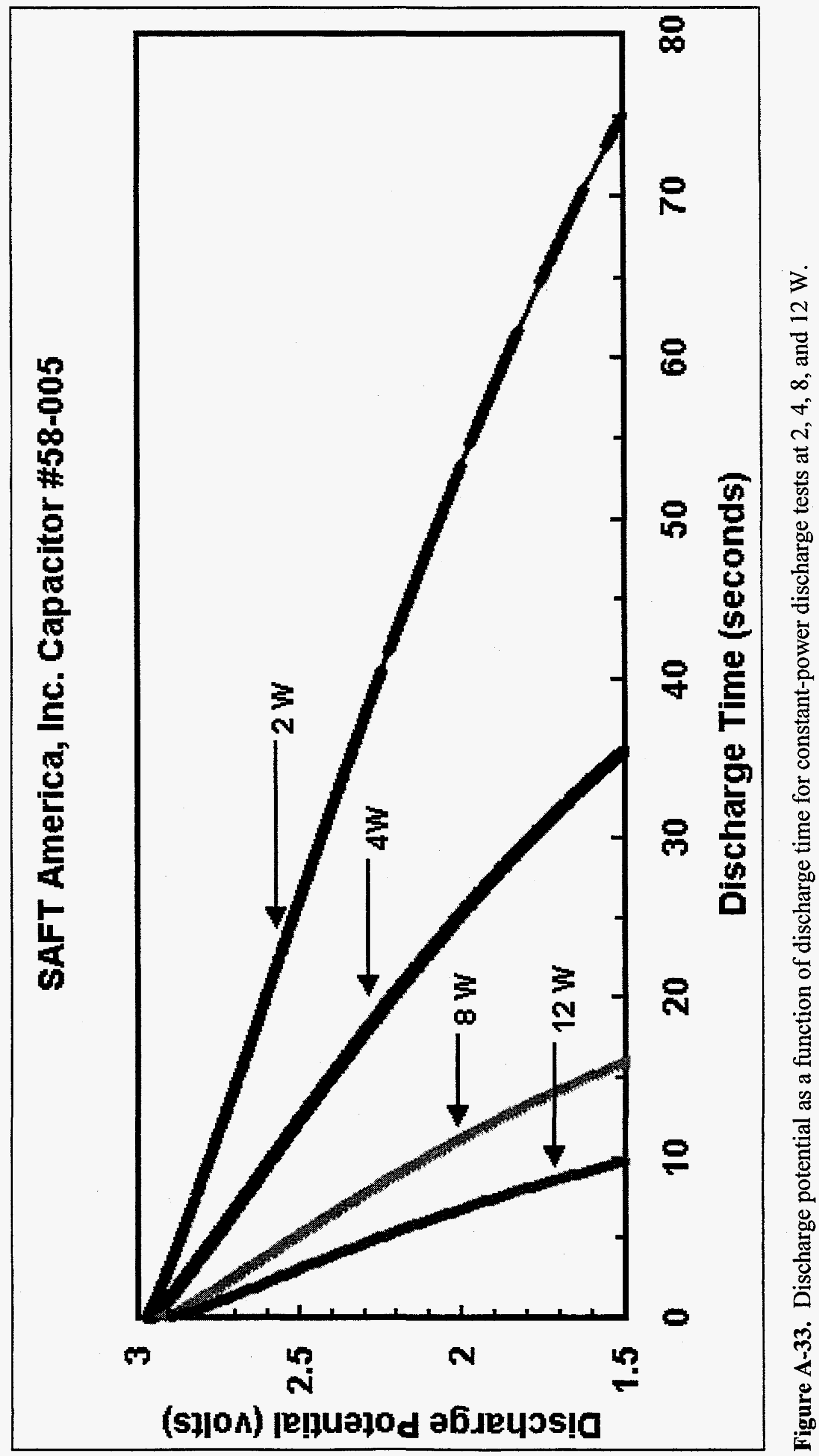




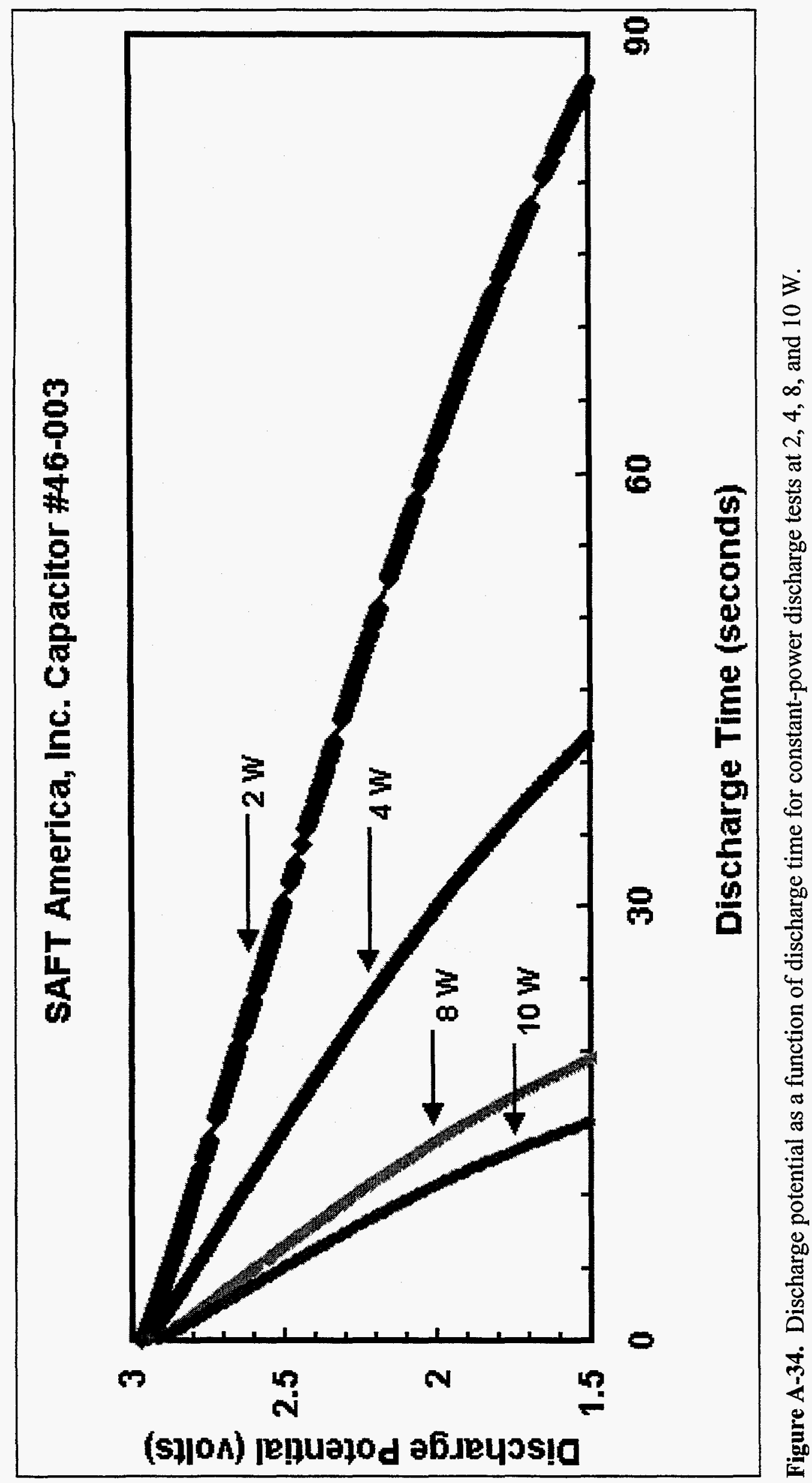




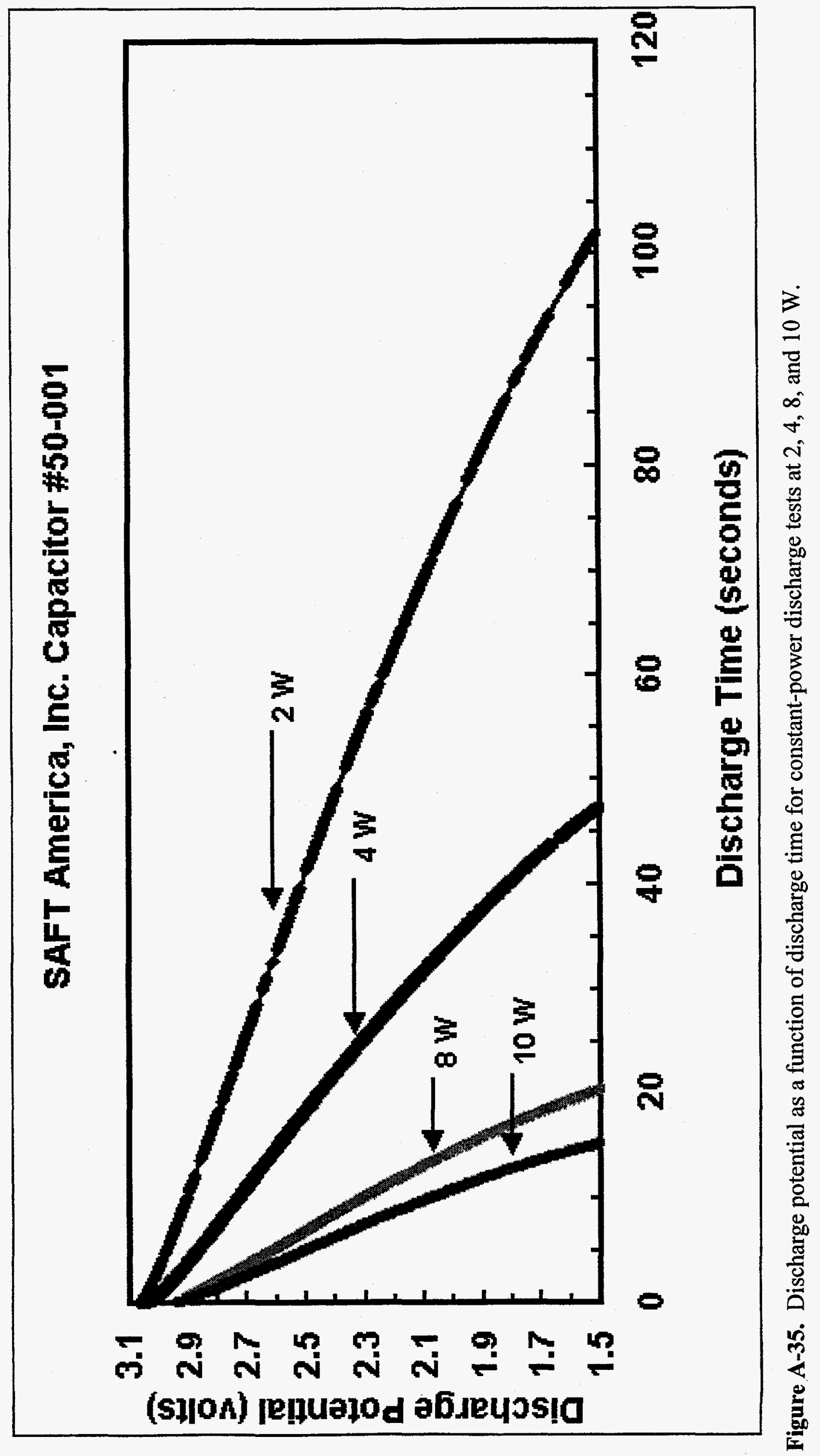




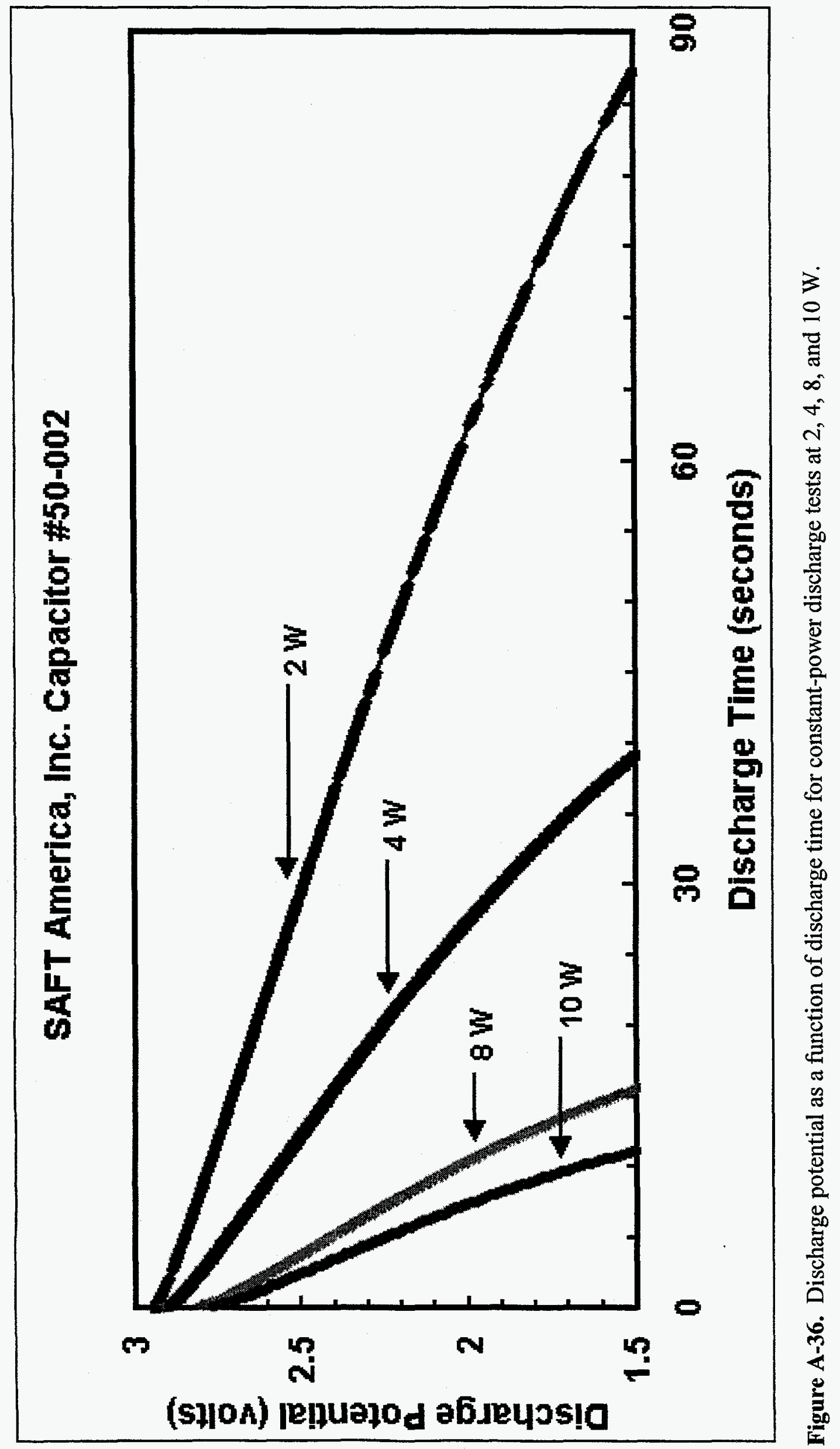

A-38 


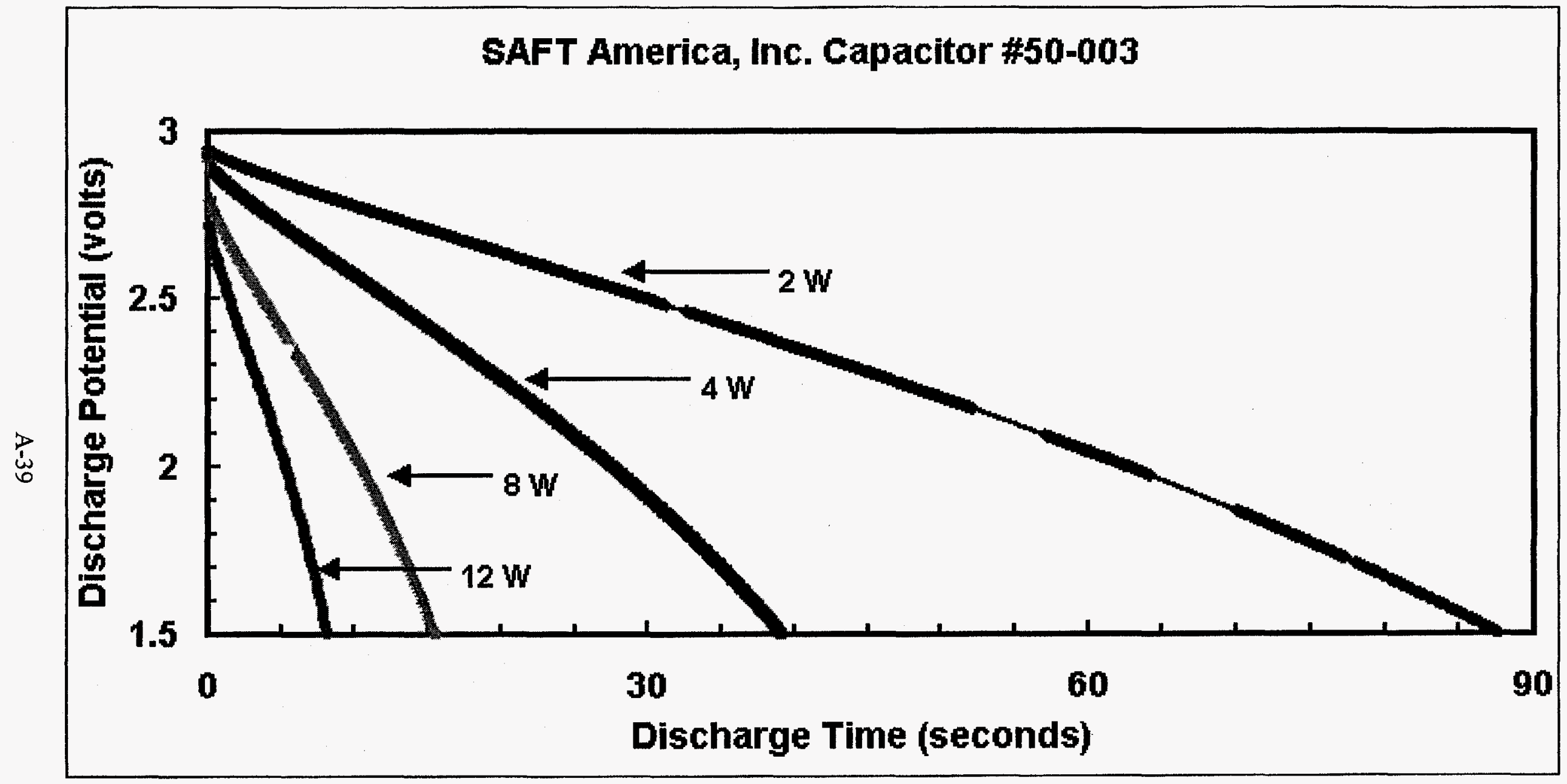

Figure A-37. Discharge potential as a function of discharge time for constant-power discharge tests at 2, 4, 8, and $12 \mathrm{~W}$. 


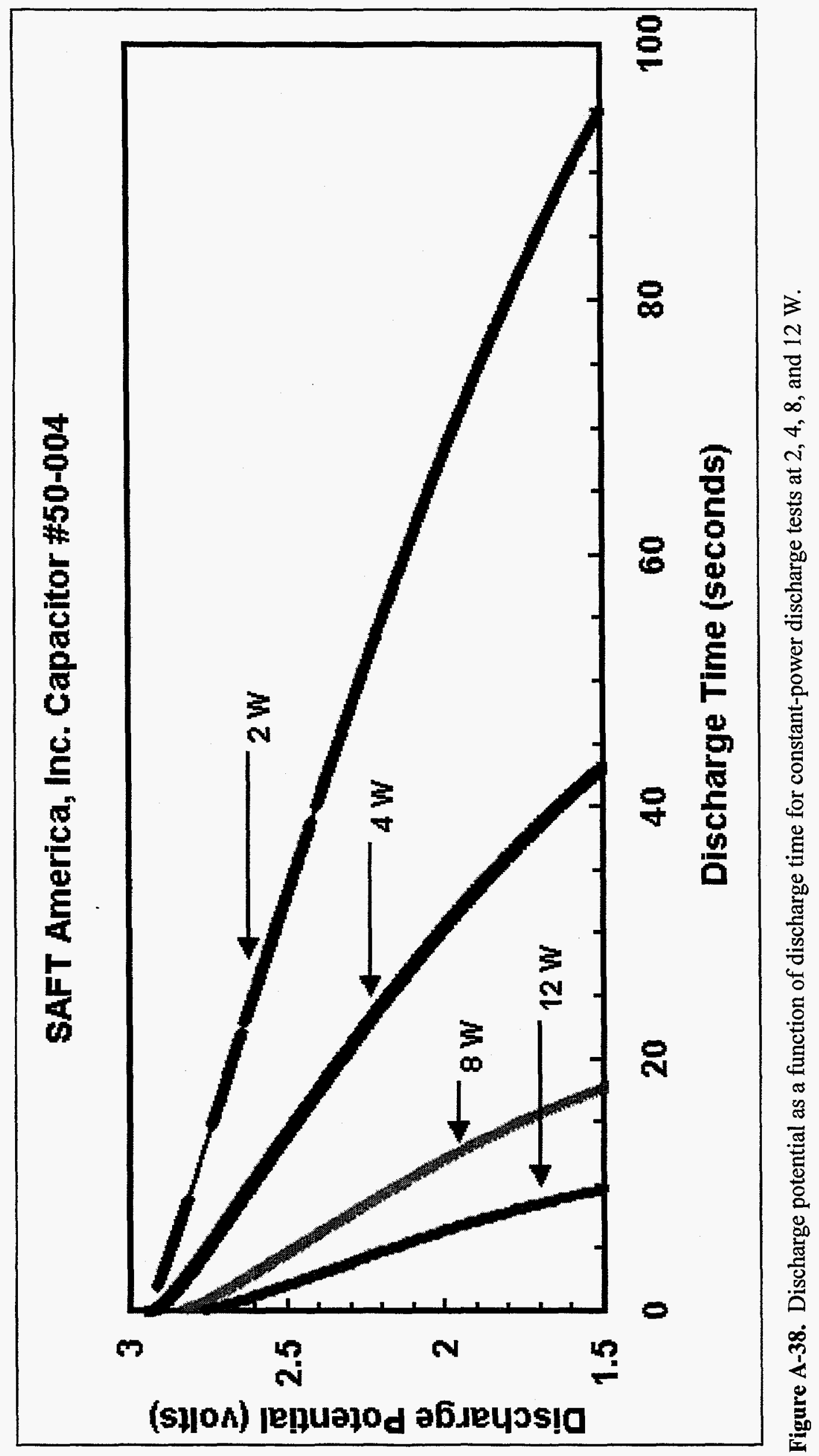




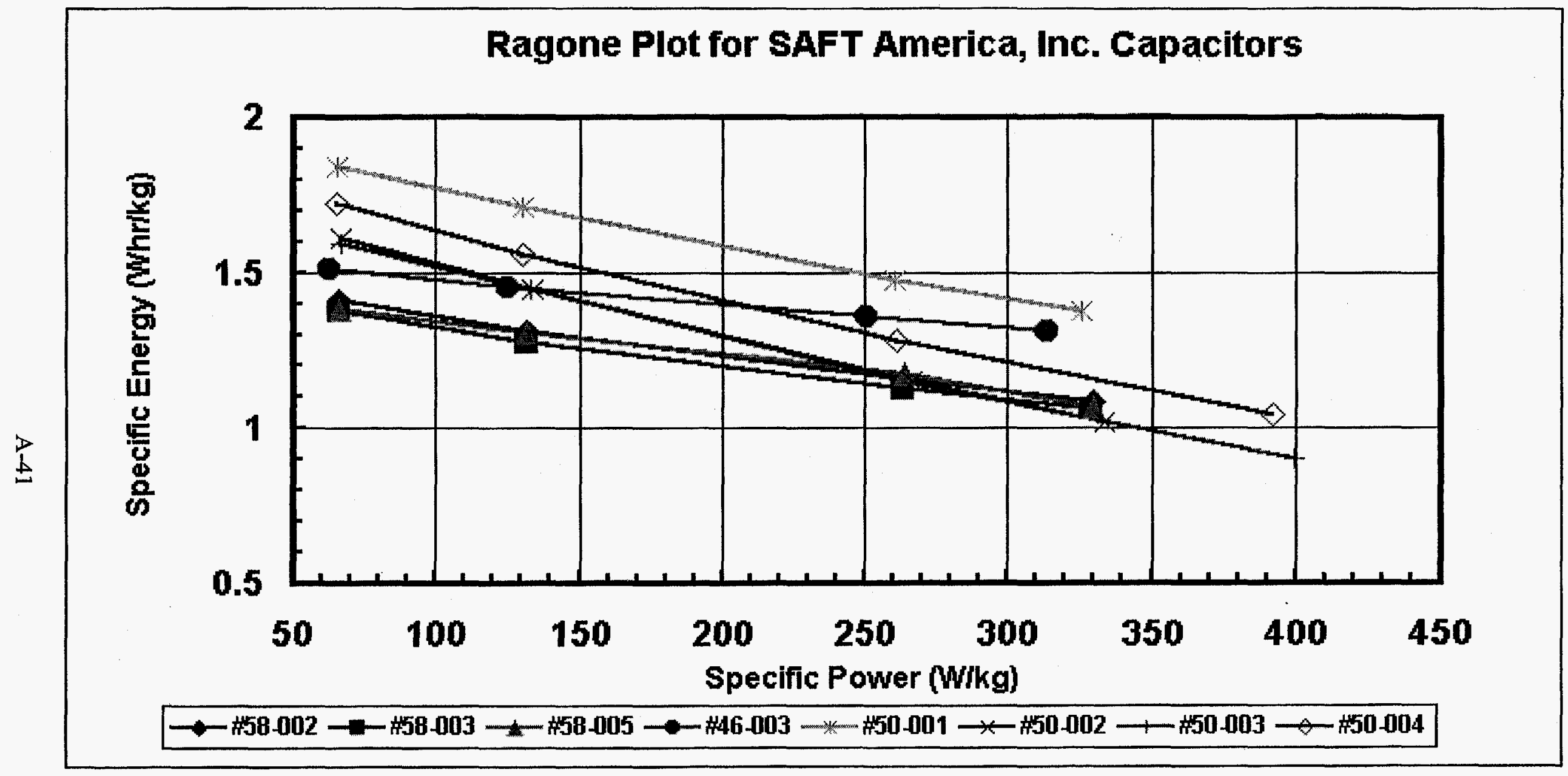

Figure A-39. Measured specific energy (Wh/kg) as a function of specific power (W/kg) as determined from the constant-power tests over a voltage range of 3 to $1.5 \mathrm{~V}$ for the eight capacitors from SAFT America, Inc. 